\title{
Toxicogenomics of A375 human malignant melanoma cells treated with arbutin
}

\author{
Sun-Long Cheng ${ }^{1}$, Rosa Huang Liu², Jin-Nan Sheu ${ }^{1}$, Shui-Tein Chen ${ }^{3,4}$, Supachok \\ Sinchaikul $^{3}$ \& Gregory Jiazer Tsay ${ }^{5, *}$ \\ ${ }^{1}$ Institute of Medicine, Chung Shan Medical University, Taichung, 40242, Taiwan; ${ }^{2}$ School of Nutrition, \\ Chung Shan Medical University, Taichung, 40242, Taiwan; ${ }^{3}$ Institute of Biological Chemistry and Genomics \\ Research Center, Academia Sinica, Taipei, 11529, Taiwan; ${ }^{4}$ Institute of Biochemical Sciences, College of Life \\ Science, National Taiwan University, Taipei, 10617, Taiwan; ${ }^{5}$ Institute of Immunology, Chung Shan Medical \\ University, 110 Sec. 1, Chien-Kuo N. Road, Taichung, 40242, Taiwan
}

Received 17 August 2006; accepted 10 October 2006

(C) 2006 National Science Council, Taipei

Key words: arbutin, A375 cells, toxicogenomics, DNA microarray, gene expression

\begin{abstract}
Summary
Although arbutin is a natural product and widely used as an ingredient in skin care products, its effect on the gene expression level of human skin with malignant melanoma cells is rarely reported. We aim to investigate the genotoxic effect of arbutin on the differential gene expression profiling in A375 human malignant melanoma cells through its effect on tumorigenesis and related side-effect. The DNA microarray analysis provided the differential gene expression pattern of arbutin-treated A375 cells with the significant changes of 324 differentially expressed genes, containing 88 up-regulated genes and 236 down-regulated genes. The gene ontology of differentially expressed genes was classified as belonging to cellular component, molecular function and biological process. In addition, four down-regulated genes of AKT1, CLECSF7, FGFR3, and LRP6 served as candidate genes and correlated to suppress the biological processes in the cell cycle of cancer progression and in the downstream signaling pathways of malignancy of melanocytic tumorigenesis.
\end{abstract}

\section{Introduction}

Arbutin, a natural compound of beta-D-glucopyranoside of hydroquinone, is widely used as an ingredient in skin care products [1]. It is effective in the treatment of various cutaneous hyperpigmentations and has the inhibitory effects on the melanogenesis in melanoma cells [2-4]. However, recent findings have raised serious questions of concern regarding both the safety and side-effect of arbutin. Although some inhibitory effects of arbutin on melanogenesis in melanoma cells and its mechanism have been elucidated, the intensive

*To whom correspondence should be addressed. Tel: + 886-424738170; Fax: +886-4-23248172; E-mail: gjt@csmu.edu.tw study of its biological effect on human genomics level in the regulation of malignant melanogenesis through the functional effect on carcinogenesis is not clear and rarely reported.

Recently, the high throughput technology of DNA microarray has become important in geneomic research and used to analyze gene expression profiling of human melanomas [5-7]. Since the study of gene expression profiling in human melanoma cells treated with arbutin has never been reported, it would be very challenging to use the DNA microarray in studying the biological effect of arbutin on malignant melanoma cells through its action on anti-cancer property. In this study, we aim to investigate the genotoxic effect of arbutin on the differential gene expression profiling 
in A375 human malignant melanoma cells through its effect on melanocytic tumorigenesis for cancer therapy and other related side-effects. We used the DNA microarray technology and bioinformatic tools to explore the differential gene expression profiling in arbutin-treated A375 cells and to classify the differentially expressed genes by Gene Oncology, which provided more understanding of the genetic basis of metabolic and cellular responses in tumergenesis of human skin cancer. In addition, we compared the biological effects of arbutin and kojic acid on differentially expressed genes in A375 cells and also proposed the hypothetical pathway of arbutin-responsive genes correlated in the suppression of tumorigenesis. These candidate genes may lead to consequently aid for early diagnostic and therapeutic applications.

\section{Materials and methods}

\section{Materials}

Human malignant melanoma cell line, A375 (CRL-1619), was obtained from the ATCC (Rockville, MD, USA). Dulbecco's Modified Eagle's Medium (DMEM), D-PBS and Trypsin-EDTA were purchased from Atlanta Biologicals (Norcross, GA, USA). Fetal bovine serum, sodium pyruvate, antibiotic-antimycotic and TRIzol reagent were purchased from Invitrogen (Carlsbad, CA, USA). Arbutin, MTT (methylthiazoletetrazolium) and sodium bicarbonate were purchased from Sigma (St. Louis, MO, USA). RNeasy Mini Kit was purchased from Qiagen (Valencia, CA, USA). Cyanine 3- and 5-labeled CTP were purchased from Perkin-Elemer/NEN Life Science (Boston, MS, USA). RNA 6000 Nano LabChip Kit, Low RNA Input Fluorescent Linear Amplification Kit, Human 1A Oligo Microarray Kit (V2), in situ Hybridization Kit Plus, and Stabilization and Drying Solution were purchased from Agilent Technologies (Palo Alto, CA, USA). All other chemicals were purchased from Sigma (St. Loius, MO, USA).

\section{Cell culture}

A375 cells were cultured in DMEM supplemented with $10 \%$ fetal bovine serum, $1.5 \mathrm{~g} / 1$ sodium bicarbonate, $1 \mathrm{mM}$ sodium pyruvate and $1 \%$ antibiotic-antimycotic in a humidified incubator with $5 \% \quad \mathrm{CO}_{2}$ and $95 \%$ air at $37^{\circ} \mathrm{C}$. Upon confluence, the cells were detached by treatment with $0.05 \%$ trypsin and $0.53 \mathrm{mM}$ EDTA. During subculture, the medium was replaced every 2-3 days.

\section{Treatment with arbutin and cell viability test}

To perform cell attachment, the cells were seeded at $5.0 \times 10^{3}$ cells/well in 96-well tissue culturetreated plates (NUNC ${ }^{\mathrm{TM}}$, Roskilde, Denmark) in $100 \mu \mathrm{l}$ of culture media. They were then washed with PBS and were cultured either alone or in the presence of various concentrations of arbutin $(0.32,1.6,8,40,200$ and $1000 \mu \mathrm{g} / \mathrm{ml})$ for $72 \mathrm{~h}$. Arbutin was suspended in $0.01 \% \mathrm{DMSO}$, and the control was added with the same concentration of DMSO in order to reduce the variation of cell growth inhibition. Triplicate experiments were done for each pair group of arbutin concentration and control. The cell viability was determined by MTT assay [8]. The percentage of cell growth inhibition was calculated as follows: Inhibition $(\%)=\left[1-\mathrm{A}_{550} \mathrm{~nm} \quad\right.$ (arbutin) $/ \mathrm{A}_{550} \mathrm{~nm} \quad$ (control)] $\times 100 \%$.

\section{$R N A$ preparation and quantitative measurement}

After the cells were treated with $8 \mu \mathrm{g} / \mathrm{ml}$ arbutin for $24 \mathrm{~h}, \mathrm{RNA}$ was extracted by a modified method using TRIzol combined with the RNeasy Mini Kit. The total RNA was quantified by a UV spectrophotometer and RNA quality was evaluated by capillary electrophoresis on an Agilent 2100 Bioanalyzer using RNA 6000 Nano LabChip Kit. For each paired sample, the number of independent paired samples of cultured cells that were treated with arbutin either present or absent was done in triplicate.

\section{$R N A$ amplification and labeling}

Targets of cRNA were amplified and fluorescently labeled from $0.5 \mu \mathrm{g}$ total RNA in each reaction using the Agilent Low RNA Input Fluorescent Linear Amplification kit. For each sample pair, the control sample was labeled with $\mathrm{Cy} 3$ and the treated sample was labeled with Cy5. After purification using Qiagen's RNeasy mini-spin 
columns, the quantification, quality and size distribution of the labeled cRNA targets were then determined by ultraviolet (UV) spectrophotometry and RNA 6000 Nano LabChip Assay.

\section{Microarray hybridization}

Hybridization was performed following the Agilent oligonucleotide microarray hybridization user's manual and Agilent in situ Hybridization Kit Plus. Briefly, $2 \mu \mathrm{g}$ of the labeled cRNA per channel was mixed with $50 \mu \mathrm{l} 10 \times$ control targets and nuclease-free water to a final volume of $240 \mu \mathrm{l}$. Each sample tube was added with $10 \mu \mathrm{l}$ of $25 \times$ fragmentation buffer and was incubated at $60{ }^{\circ} \mathrm{C}$ in a water bath in the dark for $30 \mathrm{~min}$. The reaction was then terminated by adding $250 \mu \mathrm{l}$ of $2 \times$ hybridization buffer. A volume of $500 \mu \mathrm{l}$ of hybridization mix was applied to Agilent's Human 1A Oligonucleotide Microarray, containing 20,173 (60 mer) oligonucleotide probes, and hybridized in a hybridization rotation oven at $60{ }^{\circ} \mathrm{C}$ for $17 \mathrm{~h}$. The slides which disassembled in $6 \times$ SSPE and $0.005 \% \mathrm{~N}$-Lauroylsarcosine were washed with $6 \times$ SSPE, $0.005 \% \mathrm{~N}$-Lauroylsarcosine for $1 \mathrm{~min}$ at room temperature, then with $0.06 \times \mathrm{SSPE}, 0.005 \%$ $\mathrm{N}$-Lauroylsarcosine for $1 \mathrm{~min}$ and with Stabilization and Drying Solution for $30 \mathrm{~s}$.

\section{Data analysis and bioinformatics}

The microarray chip was scanned using an Agilent G2565BA Microarray Scanner System, and the Agilent Feature Extraction software 7.5 used defaults for all parameters including a parameterized error model to compute the significance ( $p$-values) of $\log$ ratios. The image quantities of interest produced by the image analysis methods were the $(R, G)$ fluorescence intensity pairs for each gene on each array probe, where $\mathrm{R}=$ red for $\mathrm{Cy} 5$ and $\mathrm{G}=$ green for Cy3. An 'MA-plot' was used to represent the normalized $(R, G)$ data, where $\mathrm{M}=\log \mathrm{R} / \mathrm{G}$ and $\mathrm{A}=\log \sqrt{ }(\mathrm{R} \times \mathrm{G})[9]$.

For the bioinformatics tools to search gene ontology, we used the combination of databases to gain information on gene name and symbol, subcellular location, family and superfamily classification, chromosome map location, similar gene, molecular function, biochemical function-related protein and references. The gene search programs were used the following sequential order of databases: NCBI (http://www.ncbi.nlm.nih.gov), Ensembl (http://www.ensembl.org), TIGR (http:// www.tigr.org) and GeneCards (http://www.gene cards.org). In addition, the category classification of gene expression was done by in-house Bulk Gene Search System for Java (BGSSJ) program that is a searching system accomplished by open database connectivity, UniGene database and Gene Ontology knowledgebase, and is available at http://servx8.sinica.edu.tw/bgss-cgi-bin/gene.pl. On the other hand, the protein search program used the Swiss-Prot/TrEMBL (http://www.expasy.ch/sprot), Proteome (http://www.proteome.com/databases/HumanPD/reports) and PubMed (http://www.ncbi.nl.nih.gov/PubMed). Moreover, the combining pathway databases of Biocarta (http://www.biocarta.com), KEGG (http://www.genome.ad.jp/kegg/pathway.html) and the PubMed literature were used to search the correlated signaling pathways and mechanisms in the malignant melanogenesis of A375 cells.

\section{Real-time quantitative PCR ( RT-qPCR)}

Specific oligonucleotide primer pairs were designed using the analysis Beacon designer 4.00 (Premier Biosoft International) and were then used for real-time quantitative PCR. The sequences of the primers used are: (1) AKT1 (NM_005163, $150 \mathrm{bp}$ ): forward 5'-ACCATCACACCACCTGACCAAG- $3^{\prime}$ and reverse $5^{\prime}$-CGCCTCTCCATCCCTCCAAG-3'; (2) CLECSF7 (NM_130441, $184 \mathrm{bp}$ ): forward 5'-ATCAACACCAGGGAAGAACAGG- $3^{\prime}$ and reverse 5'-TCGCACAACGCTCAT CAAGG-3'; (3) FGFR3 (NM_000142, $102 \mathrm{bp}$ ): forward 5'-CTGCCAGCCGAGGAGGAG-3' and reverse 5'-CACCACCAGGATGAACAGG AAG-3'; (4) LRP6 (NM_002336, 183 bp): forward 5'-AGAATGACCTCAGTGGCAACAG-3' and reverse 5'-GGGTGGCGGTGGGTA GAG-3'. The specificity of each primer pair was tested by using a common reference RNA (Stratagene) to perform a RT-PCR reaction, followed by DNA 500 chip run on Bioanalyzer 2100 (Agilent Technologies) to check the size of the PCR product. Primer pairs of production predicted product size and no other side-product were chosen to conduct the following SYBR reaction.

Real-time quantitative PCR (RT-qPCR) was performed on the LightCycler instrument 1.5 using LightCycler ${ }^{\circledR}$ FastStart DNA Master ${ }^{P L U S}$ SYBR 
Green I kit (Roche Applied Science). Briefly, $10 \mu \mathrm{l}$ reactions, containing $2 \mu \mathrm{l}$ Master Mix, $2 \mu \mathrm{l}$ of $0.25 \mu \mathrm{M}$ gene specific primer and $6 \mu \mathrm{l}$ of cDNA, were generated as described above. Each sample, which consisted of cDNA generated from all the samples as detailed above, was run in duplicate. The PCR parameters were $95^{\circ} \mathrm{C}$ for $10 \mathrm{~s}, 45$ cycles of $95^{\circ} \mathrm{C}$ for $10 \mathrm{~s}, 60^{\circ} \mathrm{C}$ for $3 \mathrm{~s}$ and $72{ }^{\circ} \mathrm{C}$ for $10 \mathrm{~s}$. At the end of the program a melt curve analysis was made, the data were automatically analyzed by the system and an amplification plot was generated for each cDNA sample. From each of these plots, the LightCycler software calculated the threshold cycle $(\mathrm{Cp})$, defined as the fractional cycle number at which the fluorescence reached the baseline. The fold expression or repression of the target gene relative to $\beta$-actin in each sample was then calculated by the formula: profiling in A375 cells and other genotoxic sideeffects. Thus, it is very interesting to study the genotoxic effect of arbutin on human skin and on the tumorigenesis that are become our purposes of this study.

\section{Microarray analysis of differential gene expression in A375 cells after arbutin treatment}

The microarray results showed different fluorescence intensities between Cy3 (control) and Cy5 (arbutin-treated A375 cells), corresponding to the differential expression level of thousands of genes, and represented the different $\mathrm{Cy} 3$ and Cy5 signal intensities with a $p$-value of less than 0.01 $(p<0.01)$ that were considered to be significantly different (Figure 2). An analysis of gene expression changes with human oligonucleotide array re-

$$
\begin{aligned}
& 2^{-\Delta \Delta \mathrm{Cp}} \text { where } \triangle \triangle \mathrm{Cp}=\triangle \mathrm{Cp} \text { arbutin sample }-\triangle \mathrm{Cp} \text { control sample, } \\
& \triangle \mathrm{Cp} \text { arbutin sample }=\mathrm{Cp} \text { arbutin-stimulated target gene }-\mathrm{Cp} \text { arbutin-stimulated } \beta \text {-actin, } \\
& \triangle \mathrm{Cp} \text { control sample }=\mathrm{C} \mathrm{p}_{\text {control target gene }}-\mathrm{C} \mathrm{p}_{\text {control } \beta \text {-actin }}
\end{aligned}
$$

\section{Results}

\section{Inhibition effect of arbutin on A375 cells}

The cell growth of A375 cells was directly inhibited by the increase of arbutin concentrations. After $72 \mathrm{~h}$, the highest concentration of $1000 \mu \mathrm{g} / \mathrm{ml}$ arbutin allowed up to $40 \%$ inhibition of A375 cell growth, while the lower concentrations of 0.32 , $1.6,8$ and $40 \mu \mathrm{g} / \mathrm{ml}$ arbutin allowed the inhibition of cell growth by only less than $20 \%$ (Figure 1). It is indicated that the A375 cell growth was not strongly affected by all arbutin concentrations. In addition, there were no morphological changes in the cells treated with $0.32-40 \mu \mathrm{g} / \mathrm{ml}$ arbutin. According to the safety recommendation of $1 \%$ prescription of drug in human skin care product [10], the concentration of $8 \mu \mathrm{g} / \mathrm{ml}$ arbutin was appropriated in the recommended concentration. Also, there was no morphological change in the cells within $24 \mathrm{~h}$ in the presence of $8 \mu \mathrm{g} / \mathrm{ml}$ arbutin and the inhibition of cell growth was less than $10 \%$. However, it has never been reported the biological effect of arbutin on the gene expression vealed that the total number of 357 differentially expressed probes was matched with approximately 324 listed genes, containing 88 up-regulated genes (Table 1) and 236 down-regulated genes (Table 2). In addition, we used the in-house BGSSJ program to search the gene ontology that classified the gene category, according to cellular component, molecular function and biological process. The summary of the category classification of differentially expressed genes in arbutin-treated A375 cells is shown in Figure 3. The total numbers of 75 upregulated genes and 123 down-regulated genes were classified into each category with different ratios. Some of genes could be classified into more than one category, according to their cellular component, molecular function and biological process. The expressed genes were found to be located in the subcellular region rather than organelle, extracellular region, protein complex and extracellular matrix, respectively. It may indicate the signal transduction pathway occurring from extracellular region to intracellular region because some of genes served as receptors and/or transporters and have mediated the signaling genes 


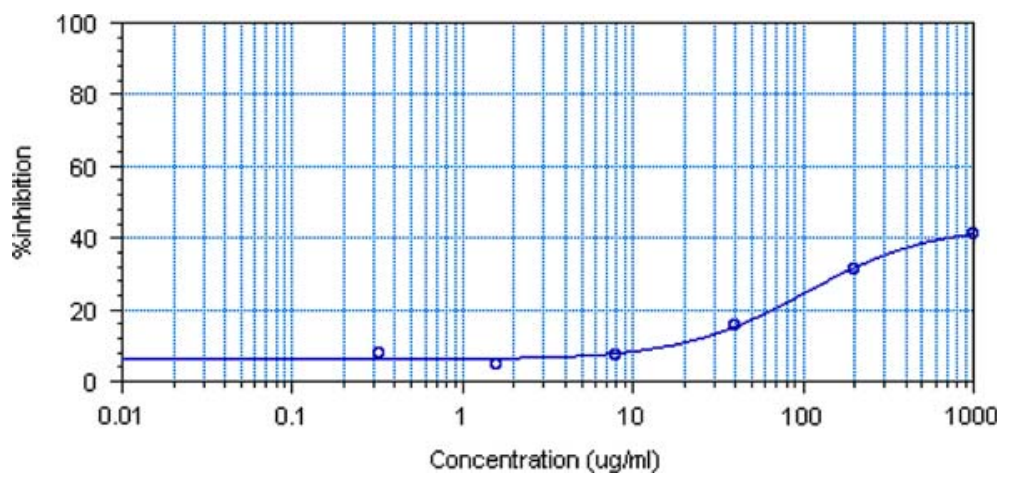

Figure 1. Effect of arbutin concentrations on the growth inhibition of A375 cells at $72 \mathrm{~h}$. The concentrations of arbutin used were $0.32,1.6,8,40,200$ and $1000 \mu \mathrm{g} / \mathrm{ml}$.

to another region. So, it is possible to be found in both regions. Otherwise, they possessed the molecular functions in different ratios of binding, catalytic activity, signal transducer activity, transcription regulator activity, enzyme regulator activity, transporter activity, structural molecule activity and translation regulator activity. Moreover, the expressed genes involved some biological processes, such as cellular process, physiological process, development and regulation of biological process. Thus, this category classification provided more useful information of gene ontology in response to arbutin treatment. Furthermore, we suggest that all of the differentially expressed genes may be regulated by various gene networks and possess related molecular functions involving biological processes in the regulation of malignant tumorigenesis.

\section{$R T-q P C R$ validation of array analysis}

The arbutin-responsive genes in A375 cells chosen for RT-qPCR analysis were selected from the order of $p$ values that were determined by microarray analysis, and from the database search of biological functions correlated with carcinogenesis. The selected genes were validated by RT-qPCR analysis to confirm the result of gene expression level with microarray data and the result of gene expression level of four expressed

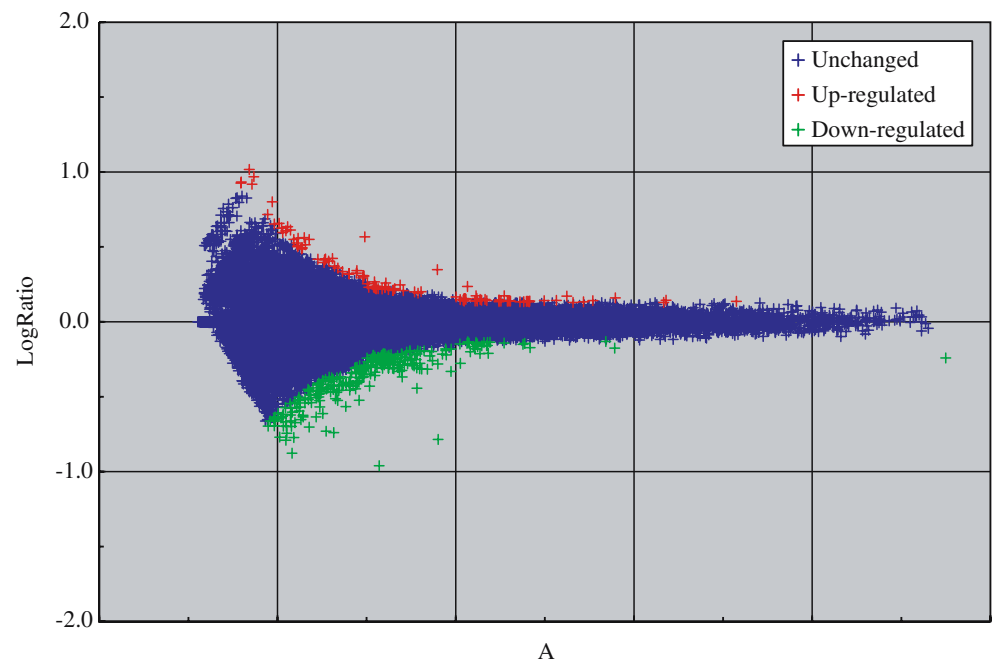

Figure 2. MA-plot of microarray data represents the differentially expressed probes of arbutin-treated A375 cells. A representative probe of comparative experiments (normal mRNA labeled with Cy3 and arbutin-treated mRNA labeled with Cy5) where R = log $(\mathrm{Cy} 5 / \mathrm{Cy} 3)$ represents the common $\log$ ratio of the two dyes and $\mathrm{A}=[\log (\mathrm{Cy} 5)+\log (\mathrm{Cy} 3)] / 2$ is the average logarithmic fluorescence intensities of both channels. The gene expression pattern shows approximately 357 significantly differentially expressed probes $(p<0.01)$. Blue + represents any data point whose log ratio is not significantly different from 0 ; red + and green + represent data points whose log ratios are greater or less than 0 , respectively $(p<0.01)$. 
Table 1. Up-regulated genes (88 genes) in arbutin-treated A375 cells.

\begin{tabular}{|c|c|c|c|c|}
\hline Gene name & Accession no. & Ratio & $p$ Value & Description \\
\hline A_23_P170387 & A_23_P170387 & 10.41 & $3.28 \mathrm{E}-07$ & Unknown \\
\hline KLHL13 & NM_033495 & 9.31 & $4.34 \mathrm{E}-07$ & Kelch-like 13 (Drosophila) (KLHL13) \\
\hline EPX & NM_000502 & 8.42 & $3.14 \mathrm{E}-05$ & Eosinophil peroxidase (EPX) \\
\hline $\mathrm{TSC} 1$ & NM_000368 & 8.31 & $3.02 \mathrm{E}-06$ & Tuberous sclerosis 1 (TSC1) \\
\hline SCN1B & NM_001037 & 6.32 & $8.38 \mathrm{E}-07$ & Sodium channel, voltage-gated, type I, beta (SCN1B), transcript variant a \\
\hline A_23_P86598 & A_23_P86598 & 5.20 & $3.15 \mathrm{E}-05$ & Unknown \\
\hline GAGED3 & NM_130777 & 4.54 & $1.86 \mathrm{E}-05$ & G antigen, family D, 3 (GAGED3) \\
\hline IL3RA & NM_002183 & 4.50 & $5.11 \mathrm{E}-05$ & Interleukin 3 receptor, alpha (low affinity) (IL3RA) \\
\hline A_23_P32966 & A_23_P32966 & 4.31 & $6.51 \mathrm{E}-06$ & Unknown \\
\hline FBXO16 & NM_172366 & 4.22 & $2.94 \mathrm{E}-05$ & F-box only protein 16 (FBXO16) \\
\hline VPS39 & NM_015289 & 4.10 & $7.83 \mathrm{E}-06$ & Vacuolar protein sorting 39 (yeast) (VPS39) \\
\hline PARG & NM_003631 & 4.05 & $2.23 \mathrm{E}-05$ & Poly (ADP-ribose) glycohydrolase (PARG) \\
\hline NRP2 & NM_201266 & 3.94 & $5.99 \mathrm{E}-05$ & Neuropilin 2 (NRP2), transcript variant 1, mRNA \\
\hline ANKRD23 & NM_144994 & 3.65 & $2.80 \mathrm{E}-06$ & Ankyrin repeat domain 23 (ANKRD23) \\
\hline FLJ13611 & NM_024941 & 3.61 & $1.22 \mathrm{E}-05$ & Hypothetical protein FLJ13611 (FLJ13611) \\
\hline THC1991976 & THC1991976 & 3.55 & $3.44 \mathrm{E}-05$ & $\begin{array}{l}\text { AF2 } 244540 \text { immunodominant membrane protein precursor }\{\text { Aster yellows } \\
\text { phytoplasma\} }\end{array}$ \\
\hline AEBP2 & NM_153207 & 3.54 & $1.63 \mathrm{E}-06$ & AE binding protein 2 (AEBP2) \\
\hline ZBTB20 & NM_015642 & 3.36 & 4.44E-05 & Zinc finger protein 288 (ZNF288) \\
\hline NR2F1 & NM_005654 & 3.27 & $1.43 \mathrm{E}-05$ & Nuclear receptor subfamily 2 , group F, member 1 (NR2F1) \\
\hline KLRC4 & NM_013431 & 3.24 & $6.16 \mathrm{E}-05$ & Killer cell lectin-like receptor subfamily C, member 4 (KLRC4) \\
\hline CAPNS2 & NM_032330 & 3.17 & $8.71 \mathrm{E}-05$ & Calpain small subunit 2 (CAPNS2) \\
\hline APOM & NM_019101 & 3.12 & $5.14 \mathrm{E}-05$ & Apolipoprotein M (APOM) \\
\hline SLC23A3 & NM_144712 & 2.65 & $5.34 \mathrm{E}-06$ & Solute carrier family 23 (nucleobase transporters), member 3 (SLC23A3) \\
\hline A_23_P10060 & A_23_P10060 & 2.62 & $2.04 \mathrm{E}-05$ & Unknown \\
\hline C18orf11 & NM_022751 & 2.62 & $7.04 \mathrm{E}-05$ & Chromosome 18 open reading frame $11(\mathrm{C} 18$ orf 11$)$ \\
\hline DDEF1 & NM_018482 & 2.58 & $3.21 \mathrm{E}-05$ & Development and differentiation enhancing factor 1 (DDEF1) \\
\hline HIST1H2AC & NM_003512 & 2.55 & $2.23 \mathrm{E}-05$ & Histone 1, H2ac (HIST1H2AC) \\
\hline HH114 & NM_032499 & 2.49 & $6.79 \mathrm{E}-05$ & Hypothetical protein HH114 (HH114) \\
\hline CPE & NM_001873 & 2.35 & 4.34E-05 & Carboxypeptidase E (CPE) \\
\hline TARDBP & NM_007375 & 2.28 & $4.80 \mathrm{E}-05$ & TAR DNA binding protein (TARDBP) \\
\hline ADAM7 & NM_003817 & 2.20 & $8.80 \mathrm{E}-06$ & A disintegrin and metalloproteinase domain 7 (ADAM7) \\
\hline KIAA1706 & NM_030636 & 2.16 & $7.74 \mathrm{E}-05$ & KIAA1706 protein (KIAA1706) \\
\hline CCAR1 & NM_018237 & 2.11 & $2.38 \mathrm{E}-05$ & Cell division cycle and apoptosis regulator 1 (CCAR 1$)$ \\
\hline CPNE5 & NM_020939 & 2.10 & $6.83 \mathrm{E}-05$ & Copine V (CPNE5) \\
\hline A_23_P251953 & A_23_P251953 & 2.09 & $7.22 \mathrm{E}-05$ & Unknown \\
\hline GPR32 & NM_001506 & 2.04 & $2.59 \mathrm{E}-05$ & G protein-coupled receptor 32 (GPR32) \\
\hline HAND1 & NM_004821 & 2.02 & $2.72 \mathrm{E}-05$ & Heart and neural crest derivatives expressed 1 (HAND1) \\
\hline TCF12 & NM_207038 & 1.97 & $6.27 \mathrm{E}-05$ & $\begin{array}{l}\text { Transcription factor } 12 \text { (HTF4, helix-loop-helix transcription factors } 4) \\
\text { (TCF12), transcript variant } 4\end{array}$ \\
\hline GPD2 & NM_000408 & 1.85 & $9.10 \mathrm{E}-05$ & Glycerol-3-phosphate dehydrogenase 2 (mitochondrial) (GPD2) \\
\hline RAB3GAP & D31886 & 1.81 & $6.14 \mathrm{E}-05$ & KIAA0066 \\
\hline DNAJB9 & NM_012328 & 1.76 & $5.26 \mathrm{E}-05$ & DnaJ (Hsp40) homolog, subfamily B, member 9 (DNAJB9) \\
\hline MCM8 & NM_032485 & 1.73 & 0.000405 & $\begin{array}{l}\text { MCM8 minichromosome maintenance deficient } 8 \text { (S. cerevisiae) } \\
\text { (MCM8), transcript variant } 1\end{array}$ \\
\hline ВC029424 & ВC029424 & 1.71 & 0.000766 & cDNA clone MGC:32677 IMAGE:4285958 \\
\hline FKSG43 & NM_032033 & 1.71 & 0.000588 & FKSG43 gene (FKSG43) \\
\hline CYP2U1 & NM_183075 & 1.70 & 0.000978 & Cytochrome P450, family 2, subfamily U, polypeptide 1 (CYP2U1) \\
\hline FLJ40432 & NM_152523 & 1.70 & 0.000645 & Hypothetical protein FLJ40432 (FLJ40432) \\
\hline
\end{tabular}


Table 1. Continued.

\begin{tabular}{|c|c|c|c|c|}
\hline Gene name & Accession no. & Ratio & $p$ Value & Description \\
\hline SPATA13 & NM_153023 & 1.69 & 0.000371 & Spermatogenesis associated 13 (SPATA13) \\
\hline ECE1 & NM_001397 & 1.68 & 0.000863 & Endothelin converting enzyme 1 (ECE1) \\
\hline MGC12466 & NM_033213 & 1.66 & 0.000982 & Hypothetical protein MGC12466 (MGC12466) \\
\hline NEU4 & NM_080741 & 1.66 & 0.000833 & Sialidase 4 (NEU4) \\
\hline TES & NM_152829 & 1.66 & 0.000333 & Testis derived transcript ( 3 LIM domains) (TES), transcript variant 2 \\
\hline POLE2 & NM_002692 & 1.64 & 0.000625 & Polymerase (DNA directed), epsilon 2 (p59 subunit) (POLE2) \\
\hline GALC & NM_000153 & 1.63 & 0.000618 & Galactosylceramidase (Krabbe disease) (GALC) \\
\hline DLGAP4 & NM_014902 & 1.62 & 0.0007 & $\begin{array}{l}\text { Discs, large (Drosophila) homolog-associated protein } 4 \text { (DLGAP4), } \\
\text { transcript variant } 1\end{array}$ \\
\hline INPP4B & NM_003866 & 1.58 & 0.000504 & Inositol polyphosphate-4-phosphatase, type II, 105kDa (INPP4B) \\
\hline ELKS & NM_178037 & 1.55 & 0.000781 & Rab6-interacting protein 2 (ELKS), transcript variant beta \\
\hline FAM49B & NM_016623 & 1.49 & 0.00073 & Hypothetical protein BM-009 (BM-009) \\
\hline MKI67 & NM_002417 & 1.49 & 0.00069 & Antigen identified by monoclonal antibody Ki-67 (MKI67) \\
\hline RNF134 & NM_032154 & 1.49 & 0.000814 & Ring finger protein 134 (RNF134) \\
\hline NMI & NM_004688 & 1.47 & 0.000352 & N-myc (and STAT) interactor (NMI) \\
\hline EFTUD1 & NM_024580 & 1.43 & 0.00258 & Hypothetical protein FLJ13119 (FLJ13119) \\
\hline IQCB1 & NM_014642 & 1.43 & 0.00317 & IQ calmodulin-binding motif containing 1 (IQCB1) \\
\hline UBQLN1 & NM_013438 & 1.43 & 0.00305 & Ubiquilin 1 (UBQLN1), transcript variant 1 \\
\hline ANKRD17 & NM_032217 & 1.41 & 0.00391 & Ankyrin repeat domain 17 (ANKRD17), transcript variant 1 \\
\hline EPS8 & NM_004447 & 1.41 & 0.00383 & Epidermal growth factor receptor pathway substrate 8 (EPS8) \\
\hline HIST1H1A & NM_005325 & 1.41 & 0.00382 & Histone 1, H1a (HIST1H1A) \\
\hline FBXO11 & NM_025133 & 1.40 & 0.00418 & F-box only protein 11 (FBXO11), transcript variant 1 \\
\hline HUMAUANTIG & NM_013285 & 1.40 & 0.0048 & Nucleolar GTPase (HUMAUANTIG) \\
\hline RPS6KA3 & NM_004586 & 1.40 & 0.00514 & Ribosomal protein S6 kinase, 90kDa, polypeptide 3 (RPS6KA3) \\
\hline A_23_P17152 & A_23_P17152 & 1.39 & 0.00504 & Unknown \\
\hline СCT8 & D13627 & 1.39 & 0.00404 & KIAA0002 \\
\hline DDX46 & NM_014829 & 1.39 & 0.00499 & DEAD (Asp-Glu-Ala-Asp) box polypeptide 46 (DDX46) \\
\hline HTATSF1 & NM_014500 & 1.39 & 0.00475 & HIV TAT specific factor 1 (HTATSF1) \\
\hline BNIP2 & NM_004330 & 1.38 & 0.00782 & BCL2/adenovirus E1B 19kDa interacting protein 2 (BNIP2) \\
\hline CGI-94 & NM_016037 & 1.38 & 0.0049 & Comparative gene identification transcript 94 (CGI-94) \\
\hline OSBPL11 & NM_022776 & 1.38 & 0.00687 & Oxysterol binding protein-like 11 (OSBPL11) \\
\hline PITPNB & NM_012399 & 1.38 & 0.00591 & Phosphotidylinositol transfer protein, beta (PITPNB) \\
\hline PPHLN1 & NM_201515 & 1.38 & 0.00613 & Periphilin 1 (PPHLN1), transcript variant 2 \\
\hline SPTLC1 & NM_006415 & 1.38 & 0.00681 & $\begin{array}{l}\text { Serine palmitoyltransferase, long chain base subunit } 1 \text { (SPTLC1), } \\
\text { transcript variant } 1\end{array}$ \\
\hline BCAS2 & NM_005872 & 1.37 & 0.0078 & Breast carcinoma amplified sequence 2 (BCAS2) \\
\hline C20orf36 & NM_018257 & 1.37 & 0.00705 & Chromosome 20 open reading frame 36 (C20orf36) \\
\hline KDELC1 & NM_024089 & 1.37 & 0.00851 & KDEL (Lys-Asp-Glu-Leu) containing 1 (KDELC1) \\
\hline PGM2 & NM_018290 & 1.37 & 0.00679 & Phosphoglucomutase 2 (PGM2) \\
\hline SF3B1 & NM_012433 & 1.37 & 0.0066 & Splicing factor $3 \mathrm{~b}$, subunit $1,155 \mathrm{kDa}$ (SF3B1) \\
\hline CRI1 & NM_014335 & 1.36 & 0.00788 & CREBBP/EP300 inhibitory protein 1 (CRI1) \\
\hline TMEM32 & NM_173470 & 1.36 & 0.008 & Hypothetical protein LOC93380 (LOC93380) \\
\hline ARL6IP & NM_015161 & 1.35 & 0.00971 & ADP-ribosylation factor-like 6 interacting protein (ARL6IP) \\
\hline CGI-49 & NM_016002 & 1.35 & 0.00979 & CGI-49 protein (CGI-49) \\
\hline
\end{tabular}

genes was agreed with the DNA microarray expression data (Table 3). There were v-akt murine thymoma viral oncogene homolog 1 (AKT1), c-type (calcium dependent, carbohy- drate-recognition domain) lectin, superfamily member 7 (CLECSF7) or C-type lectin domain family 4, member C (CLEC4C), fibroblast growth factor receptor 3 (FGFR3) and low density 
Table 2. Down-regulated genes (236 genes) in arbutin-treated A375 cells.

\begin{tabular}{|c|c|c|c|c|}
\hline Gene name & Accession no. & Ratio & $p$ Value & Description \\
\hline $7 \mathrm{~h} 3$ & NM_033025 & 0.74 & 0.00989 & Homo sapiens hypothetical protein FLJ13511 (7h3) \\
\hline ATAD3B & NM_031921 & 0.74 & 0.00887 & ATPase family, AAA domain containing 3B (ATAD3B) \\
\hline ARFIP2 & NM_012402 & 0.73 & 0.00693 & ADP-ribosylation factor interacting protein 2 (arfaptin 2) (ARFIP2) \\
\hline ASNA1 & NM_004317 & 0.73 & 0.00759 & ArsA arsenite transporter, ATP-binding, homolog 1 (bacterial) (ASNA1) \\
\hline MGC1203 & NM_024296 & 0.73 & 0.00731 & Hypothetical protein MGC1203 (MGC1203) \\
\hline RGS19IP1 & NM_005716 & 0.73 & 0.0074 & Regulator of G-protein signaling 19 interacting protein 1 (RGS19IP1) \\
\hline PIN1 & NM_006221 & 0.72 & 0.00526 & Protein (peptidyl-prolyl cis/trans isomerase) NIMA-interacting 1 (PIN1) \\
\hline PSMD13 & NM_175932 & 0.72 & 0.00461 & $\begin{array}{l}\text { Proteasome (prosome, macropain) } 26 \mathrm{~S} \text { subunit, non-ATPase, } 13 \\
\text { (PSMD13) }\end{array}$ \\
\hline SSP411 & NM_022827 & 0.72 & 0.00595 & Hypothetical protein FLJ21347 (FLJ21347) \\
\hline CBX6 & NM_014292 & 0.71 & 0.00474 & Chromobox homolog 6 (CBX6) \\
\hline CD151 & NM_004357 & 0.71 & 0.00415 & CD151 antigen (CD151) \\
\hline JUN & NM_002228 & 0.71 & 0.00434 & v-Jun sarcoma virus 17 oncogene homolog (avian) (JUN) \\
\hline PSMD3 & NM_002809 & 0.71 & 0.00298 & Proteasome (prosome, macropain) 26S subunit, non-ATPase, 3 (PSMD3) \\
\hline ARHGEF2 & NM_004723 & 0.70 & 0.00218 & Rho/Rac guanine nucleotide exchange factor (GEF) 2 (ARHGEF2) \\
\hline $\mathrm{CD} 2 \mathrm{BP} 2$ & NM_006110 & 0.70 & 0.0022 & CD2 antigen (cytoplasmic tail) binding protein 2 (CD2BP2) \\
\hline MGC5395 & NM_024060 & 0.69 & 0.00159 & Hypothetical protein MGC5395 (MGC5395) \\
\hline PIGQ & NM_004204 & 0.69 & 0.00196 & Phosphatidylinositol glycan, class Q (PIGQ), transcript variant 2 \\
\hline DPP7 & NM_013379 & 0.68 & 0.00152 & Dipeptidylpeptidase 7 (DPP7) \\
\hline SDC4 & NM_002999 & 0.67 & 0.000717 & Syndecan 4 (amphiglycan, ryudocan) (SDC4) \\
\hline UBE2M & NM_003969 & 0.67 & 0.000537 & Ubiquitin-conjugating enzyme E2M (UBC12 homolog, yeast) (UBE2M) \\
\hline AP1S1 & NM_057089 & 0.66 & 0.000638 & Adaptor-related protein complex 1, sigma 1 subunit (AP1S1) \\
\hline APTX & NM_175073 & 0.66 & 0.000804 & Aprataxin (APTX), transcript variant 1, mRNA \\
\hline ARL2 & NM_001667 & 0.66 & 0.00061 & ADP-ribosylation factor-like 2 (ARL2 \\
\hline Beta4GalNAc-T4 & NM_178537 & 0.64 & 0.000641 & Hypothetical protein FLJ25045 (FLJ25045) \\
\hline BQ189193 & BQ189193 & 0.64 & 0.000536 & cDNA clone UI-E-EJ1-ajv-o-09-0-UI 5', mRNA \\
\hline DPYSL2 & NM_001386 & 0.64 & 0.000382 & Dihydropyrimidinase-like 2 (DPYSL2) \\
\hline FTHFSDC1 & NM_015440 & 0.64 & 0.000892 & Formyltetrahydrofolate synthetase domain containing 1 (FTHFSDC1) \\
\hline ADRB3 & NM_000025 & 0.63 & 0.000605 & Adrenergic, beta-3-, receptor (ADRB3) \\
\hline HOXB8 & NM_024016 & 0.63 & 0.000603 & Homeo box B8 (HOXB8) \\
\hline ILT10 & NM_024317 & 0.63 & 0.000451 & $\begin{array}{l}\text { Leukocyte immunoglobulin-like receptor, subfamily A (without TM do- } \\
\text { main), member } 5 \text { (ILT10) }\end{array}$ \\
\hline MAFK & NM_002360 & 0.63 & 0.000352 & $\begin{array}{l}\text { v-Maf musculoaponeurotic fibrosarcoma oncogene homolog K (avian) } \\
\text { (MAFK) }\end{array}$ \\
\hline SYMPK & NM_004819 & 0.62 & $5.93 \mathrm{E}-05$ & Symplekin (SYMPK) \\
\hline A_23_P123389 & A_23_P123 389 & 0.61 & 0.000899 & Unknown \\
\hline ENST00000329 & ENST00000 & 0.61 & 0.000304 & Xenobiotic/medium-chain fatty acid:CoA ligase \\
\hline 697 & 329697 & & & \\
\hline FLJ12242 & NM_024681 & 0.61 & 0.00089 & Hypothetical protein FLJ12242 (FLJ12242) \\
\hline GPRC5D & NM_018654 & 0.61 & 0.000349 & G protein-coupled receptor, family C, group 5 , member D (GPRC5D) \\
\hline INA & NM_032727 & 0.61 & 0.000181 & Internexin neuronal intermediate filament protein, alpha (INA) \\
\hline MGC33867 & ВC004501 & 0.61 & $5.93 \mathrm{E}-05$ & Hypothetical protein MGC33867 (cDNA clone IMAGE:3835289) \\
\hline PCTK1 & NM_033018 & 0.61 & $7.91 \mathrm{E}-05$ & PCTAIRE protein kinase 1 (PCTK1) \\
\hline PUNC & NM_004884 & 0.61 & 0.000473 & Putative neuronal cell adhesion molecule (PUNC) \\
\hline CREBL1 & NM_004381 & 0.60 & $4.72 \mathrm{E}-05$ & cAMP responsive element binding protein-like 1 (CREBL1) \\
\hline KLPH & NM_207338 & 0.60 & 0.000992 & $\begin{array}{l}\text { Likely ortholog of mouse klotho lactase-phlorizin hydrolase related pro- } \\
\text { tein }(\mathrm{KLPH})\end{array}$ \\
\hline NYD-SP29 & NM_145172 & 0.60 & 0.000941 & Testis development protein NYD-SP29 (NYD-SP29) \\
\hline
\end{tabular}


Table 2. Continued.

\begin{tabular}{|c|c|c|c|c|}
\hline Gene name & Accession no. & Ratio & $p$ Value & Description \\
\hline OR8B8 & $\begin{array}{l}\text { ENST00000 } \\
327930\end{array}$ & 0.60 & 0.000414 & $\begin{array}{l}\text { Olfactory receptor } 8 \mathrm{~B} 8 \text { (Olfactory receptor TPCR85) (Olfactory-like } \\
\text { receptor JCG8) [Source:SWISSPROT;Acc:Q15620] }\end{array}$ \\
\hline TULP3 & AF045583 & 0.60 & 0.000618 & Tubby like protein 3 (TULP3) \\
\hline MGC35308 & NM_175922 & 0.59 & $4.91 \mathrm{E}-05$ & Hypothetical protein MGC35308 (MGC35308) \\
\hline OTX1 & NM_014562 & 0.59 & 0.000342 & Orthodenticle homolog 1 (Drosophila) (OTX1) \\
\hline SNIP1 & NM_024700 & 0.59 & 0.000202 & Smad nuclear interacting protein (SNIP1) \\
\hline CEACAM 1 & NM_001712 & 0.58 & 0.000249 & $\begin{array}{l}\text { Carcinoembryonic antigen-related cell adhesion molecule } 1 \text { (biliary gly- } \\
\text { coprotein) (CEACAM1) }\end{array}$ \\
\hline DLX1 & NM_178120 & 0.58 & 0.000192 & Distal-less homeo box 1 (DLX1) \\
\hline FAM3D & NM_138805 & 0.58 & 0.000344 & Family with sequence similarity 3 , member D (FAM3D) \\
\hline KIAA1811 & NM_032430 & 0.58 & 0.000299 & KIAA1811 protein (KIAA1811) \\
\hline MIDN & AK075506 & 0.58 & $7.37 \mathrm{E}-05$ & cDNA PSEC0204 fis, clone HEMBA1002706. \\
\hline MS4A6E & NM_139249 & 0.58 & 0.000482 & Membrane-spanning 4-domains, subfamily A, member 6E (MS4A6E) \\
\hline SFXN2 & NM_178858 & 0.58 & 0.00037 & Sideroflexin 2 (SFXN2) \\
\hline UPLC1 & NM_017707 & 0.58 & 0.000303 & Up-regulated in liver cancer 1 (UPLC1) \\
\hline ZFP67 & NM_015872 & 0.58 & 0.000314 & Zinc finger protein 67 homolog (mouse) (ZFP67) \\
\hline GPR26 & NM_153442 & 0.57 & $8.11 \mathrm{E}-05$ & G protein-coupled receptor 26 (GPR26) \\
\hline KIAA0669 & NM_014779 & 0.57 & 0.000263 & KIAA0669 gene product (KIAA0669) \\
\hline LOC83468 & NM_031302 & 0.57 & 0.000162 & Gycosyltransferase (LOC83468) \\
\hline MAPK8 & NM_002750 & 0.57 & 0.000385 & Mitogen-activated protein kinase 8 (MAPK8) \\
\hline SERPINA5 & NM_000624 & 0.57 & $2.64 \mathrm{E}-05$ & $\begin{array}{l}\text { Serine (or cysteine) proteinase inhibitor, clade A (alpha-1 antiproteinase, } \\
\text { antitrypsin), member } 5 \text { (SERPINA5) }\end{array}$ \\
\hline TREH & NM_007180 & 0.57 & 0.000633 & Trehalase (brush-border membrane glycoprotein) (TREH) \\
\hline $\mathrm{AKT}^{\mathrm{a}}$ & NM_005163 & 0.56 & $2.14 \mathrm{E}-05$ & v-Akt murine thymoma viral oncogene homolog 1 (AKT1) \\
\hline MGC33407 & NM_178525 & 0.56 & $6.68 \mathrm{E}-05$ & Hypothetical protein MGC33407 (MGC33407) \\
\hline MVD & NM_002461 & 0.56 & 0.000205 & Mevalonate (diphospho) decarboxylase (MVD) \\
\hline PRRX1 & NM_006902 & 0.56 & $1.66 \mathrm{E}-05$ & Paired related homeobox 1 (PRRX1) \\
\hline RAB6B & NM_016577 & 0.56 & $6.40 \mathrm{E}-05$ & RAB6B, member RAS oncogene family (RAB6B) \\
\hline SERPIND1 & NM_000185 & 0.56 & $9.94 \mathrm{E}-05$ & $\begin{array}{l}\text { Serine (or cysteine) proteinase inhibitor, clade D (heparin cofactor), } \\
\text { member } 1 \text { (SERPIND1) }\end{array}$ \\
\hline AFAP & NM_021638 & 0.55 & 0.000187 & Actin filament associated protein (AFAP) \\
\hline AK026716 & AK026716 & 0.55 & $6.38 \mathrm{E}-05$ & cDNA: FLJ23063 fis, clone LNG04745 \\
\hline ENPP1 & NM_006208 & 0.55 & $1.98 \mathrm{E}-05$ & Ectonucleotide pyrophosphatase/phosphodiesterase 1 (ENPP1) \\
\hline FLJ11535 & NM_024888 & 0.55 & $4.58 \mathrm{E}-06$ & Hypothetical protein FLJ11535 (FLJ11535) \\
\hline PACSIN2 & NM_007229 & 0.55 & $4.91 \mathrm{E}-05$ & Protein kinase $\mathrm{C}$ and casein kinase substrate in neurons 2 (PACSIN2) \\
\hline SLC13A2 & NM_003984 & 0.55 & 0.000104 & $\begin{array}{l}\text { Solute carrier family } 13 \text { (sodium-dependent dicarboxylate transporter), } \\
\text { member } 2 \text { (SLC13A2) }\end{array}$ \\
\hline TEX13B & NM_031273 & 0.55 & 0.000121 & Testis expressed sequence 13B (TEX13B) \\
\hline A_23_P86779 & A_23_P86779 & 0.54 & 4.10E-05 & Unknown \\
\hline A_23_P9270 & A_23_P9270 & 0.54 & $1.36 \mathrm{E}-05$ & Unknown \\
\hline AY032661 & AY032661 & 0.54 & 0.000159 & Lung squamous cell carcinoma related protein- 2 mRNA \\
\hline IFIT3 & NM_001549 & 0.54 & 0.000147 & Interferon-induced protein with tetratricopeptide repeats 4 (IFIT4) \\
\hline IL23A & NM_016584 & 0.54 & $2.18 \mathrm{E}-05$ & Interleukin 23, alpha subunit p19 (IL23A) \\
\hline NM_206995 & NM_206995 & 0.54 & $1.08 \mathrm{E}-05$ & Chromosome 10 open reading frame 1 (C10orfl) \\
\hline PRKX & NM_005044 & 0.54 & 0.000123 & Protein kinase, X-linked (PRKX) \\
\hline ACVRL1 & NM_000020 & 0.53 & $4.56 \mathrm{E}-07$ & Activin A receptor type II-like 1 (ACVRL1) \\
\hline ARX & NM_139058 & 0.53 & $1.37 \mathrm{E}-05$ & Aristaless related homeobox (ARX) \\
\hline $\mathrm{CLECSF}^{\mathrm{a}}$ & NM_130441 & 0.53 & $2.09 \mathrm{E}-05$ & $\begin{array}{l}\text { C-type (calcium dependent, carbohydrate-recognition domain) lectin, } \\
\text { superfamily member } 7 \text { (CLECSF7) }\end{array}$ \\
\hline
\end{tabular}


Table 2. Continued.

\begin{tabular}{|c|c|c|c|c|}
\hline Gene name & Accession no. & Ratio & $p$ Value & Description \\
\hline MDFI & NM_005586 & 0.53 & $1.88 \mathrm{E}-06$ & MyoD family inhibitor (MDFI) \\
\hline BST2 & NM_004335 & 0.52 & $3.58 \mathrm{E}-06$ & Bone marrow stromal cell antigen 2 (BST2) \\
\hline FLJ14442 & NM_032785 & 0.52 & $1.43 \mathrm{E}-06$ & Hypothetical protein FLJ14442 (FLJ14442) \\
\hline FLJ20245 & NM_017723 & 0.52 & $6.35 \mathrm{E}-07$ & Hypothetical protein FLJ20245 (FLJ20245) \\
\hline GPR55 & NM_005683 & 0.52 & $1.23 \mathrm{E}-05$ & G protein-coupled receptor 55 (GPR55) \\
\hline HRMT1L1 & NM_001535 & 0.52 & $3.06 \mathrm{E}-05$ & HMT1 hnRNP methyltransferase-like 1 (S. cerevisiae) (HRMT1L1) \\
\hline LRP5 & NM_002335 & 0.52 & $1.73 \mathrm{E}-05$ & Low density lipoprotein receptor-related protein 5 (LRP5) \\
\hline LRP6 $^{\mathrm{a}}$ & NM_002336 & 0.52 & $3.36 \mathrm{E}-06$ & LRP6 \\
\hline M160 & NM_174941 & 0.52 & $5.81 \mathrm{E}-06$ & Scavenger receptor cysteine-rich type 1 protein M160 (M160) \\
\hline C19orf33 & NM_033520 & 0.51 & $7.70 \mathrm{E}-07$ & Immortalization-upregulated protein (IMUP) \\
\hline FRAS1 & NM_206841 & 0.51 & $2.96 \mathrm{E}-05$ & Fraser syndrome 1 (FRAS1) \\
\hline GMPR & NM_006877 & 0.51 & $2.09 \mathrm{E}-06$ & Guanosine monophosphate reductase (GMPR) \\
\hline MGC13275 & AK 123855 & 0.51 & $8.94 \mathrm{E}-05$ & cDNA FLJ41861 fis, clone NTONG2008672 \\
\hline PRSS2 & NM_002770 & 0.51 & $3.41 \mathrm{E}-05$ & Protease, serine, 2 (trypsin 2) (PRSS2) \\
\hline SLCO5A1 & NM_030958 & 0.51 & $4.78 \mathrm{E}-05$ & Solute carrier organic anion transporter family, member $5 \mathrm{~A} 1$ (SLCO5A1) \\
\hline A_23_P89499 & A_23_P89499 & 0.50 & $8.54 \mathrm{E}-06$ & Unknown \\
\hline $\mathrm{COH} 1$ & NM_015243 & 0.50 & $7.38 \mathrm{E}-05$ & Cohen syndrome $1(\mathrm{COH} 1)$, transcript variant 3 , mRNA \\
\hline CROC4 & AK 124566 & 0.50 & $2.26 \mathrm{E}-05$ & cDNA FLJ42575 fis, clone BRACE3008237. \\
\hline NCALD & NM_032041 & 0.50 & $1.16 \mathrm{E}-06$ & Neurocalcin delta (NCALD) \\
\hline BAG5 & NM_004873 & 0.49 & $2.31 \mathrm{E}-07$ & BCL2-associated athanogene 5 (BAG5) \\
\hline BCKDK & NM_005881 & 0.49 & $1.99 \mathrm{E}-06$ & Branched chain alpha-ketoacid dehydrogenase kinase (BCKDK) \\
\hline BZRAP1 & NM_004758 & 0.49 & $1.16 \mathrm{E}-06$ & Benzodiazapine receptor (peripheral) associated protein 1 (BZRAP1) \\
\hline FGFR $^{\mathrm{a}}$ & NM_000142 & 0.49 & $8.82 \mathrm{E}-07$ & FGFR3 (achondroplasia, thanatophoric dwarfism) (FGFR3) \\
\hline KCNAB3 & NM_004732 & 0.49 & $1.78 \mathrm{E}-05$ & $\begin{array}{l}\text { Potassium voltage-gated channel, shaker-related subfamily, beta member } \\
3 \text { (KCNAB3) }\end{array}$ \\
\hline NKD1 & NM_033119 & 0.49 & $6.73 \mathrm{E}-05$ & Naked cuticle homolog 1 (Drosophila) (NKD1) \\
\hline NM_017571 & NM_017571 & 0.49 & $6.95 \mathrm{E}-05$ & Hypothetical protein LOC55580 (LOC55580) \\
\hline OLFML1 & NM_198474 & 0.49 & $2.32 \mathrm{E}-06$ & MVAL564 (UNQ564) \\
\hline OSBP2 & AF288741 & 0.49 & $1.29 \mathrm{E}-07$ & Oxysterol binding protein 2 (OSBP2) \\
\hline RASGEF1B & NM_152545 & 0.49 & $3.17 \mathrm{E}-06$ & RasGEF domain family, member 1B (RASGEF1B) \\
\hline STARD8 & NM_014725 & 0.49 & $2.71 \mathrm{E}-05$ & START domain containing 8 (STARD8) \\
\hline BTN2A1 & NM_078476 & 0.48 & $1.59 \mathrm{E}-05$ & Butyrophilin, subfamily 2, member A1 (BTN2A1) \\
\hline TRAM2 & D31762 & 0.48 & $9.80 \mathrm{E}-08$ & KIAA0057 \\
\hline ZNF497 & NM_198458 & 0.48 & $5.89 \mathrm{E}-08$ & Zinc finger protein 497 (ZNF497) \\
\hline EFNA3 & NM_004952 & 0.47 & $1.93 \mathrm{E}-07$ & Ephrin-A3 (EFNA3) \\
\hline SFRP5 & NM_003015 & 0.47 & $1.28 \mathrm{E}-05$ & Secreted frizzled-related protein 5 (SFRP5) \\
\hline SLC25A2 & NM_031947 & 0.47 & $1.39 \mathrm{E}-07$ & $\begin{array}{l}\text { Solute carrier family } 25 \text { (mitochondrial carrier; ornithine transporter) } \\
\text { member } 2 \text { (SLC25A2) }\end{array}$ \\
\hline WNT10A & NM_025216 & 0.47 & $6.74 \mathrm{E}-09$ & Wingless-type MMTV integration site family, member 10A (WNT10A) \\
\hline C19orf4 & NM_012109 & 0.46 & $1.27 \mathrm{E}-06$ & Chromosome 19 open reading frame 4 (C19orf4) \\
\hline FPGT & NM_003838 & 0.46 & $5.79 \mathrm{E}-06$ & Fucose-1-phosphate guanylyltransferase (FPGT) \\
\hline LRRTM4 & NM_024993 & 0.46 & $2.00 \mathrm{E}-05$ & Leucine-rich repeat transmembrane neuronal 4 protein (LRRTM4) \\
\hline ZNF483 & AB075842 & 0.46 & $1.37 \mathrm{E}-05$ & mRNA for KIAA1962 protein \\
\hline $\mathrm{CD} 3 \mathrm{G}$ & NM_000073 & 0.45 & $8.24 \mathrm{E}-06$ & CD3G antigen, gamma polypeptide (TiT3 complex) (CD3G) \\
\hline MGC15716 & NM_032370 & 0.45 & $1.02 \mathrm{E}-06$ & Hypothetical protein MGC15716 (MGC15716) \\
\hline A_23_P122323 & A_23_P122323 & 0.44 & $1.85 \mathrm{E}-06$ & Unknown \\
\hline MGC33637 & NM_152596 & 0.44 & $3.00 \mathrm{E}-07$ & Hypothetical protein MGC33637 (MGC33637) \\
\hline A_23_P395326 & A_23_P395326 & 0.43 & $8.31 \mathrm{E}-07$ & Unknown \\
\hline COL17A1 & NM_000494 & 0.43 & $9.87 \mathrm{E}-05$ & Collagen, type XVII, alpha 1 (COL17A1) \\
\hline
\end{tabular}


Table 2. Continued.

\begin{tabular}{|c|c|c|c|c|}
\hline Gene name & Accession no. & Ratio & $p$ Value & Description \\
\hline DNAH7 & NM_018897 & 0.43 & $7.67 \mathrm{E}-07$ & Dynein, axonemal, heavy polypeptide 7 (DNAH7) \\
\hline SLC27A4 & AF055899 & 0.43 & $6.94 \mathrm{E}-09$ & Fatty acid transport protein (FATP) \\
\hline THC1871477 & THC1871477 & 0.43 & 4.54E-06 & $\begin{array}{l}\text { ALU7_HUMAN Alu subfamily SQ sequence contamination warning } \\
\text { entry. }\end{array}$ \\
\hline AK092138 & AK092138 & 0.42 & $1.54 \mathrm{E}-05$ & cDNA FLJ34819 fis, clone NT2NE2008213 \\
\hline CNKSR2 & AF418270 & 0.42 & $9.06 \mathrm{E}-07$ & Connector enhancer of KSR2B mRNA \\
\hline ZDHHC2 & NM_016353 & 0.42 & $2.83 \mathrm{E}-05$ & Zinc finger, DHHC domain containing 2 (ZDHHC2) \\
\hline $\mathrm{ZP} 2$ & NM_003460 & 0.42 & $5.84 \mathrm{E}-05$ & Zona pellucida glycoprotein 2 (sperm receptor) (ZP2) \\
\hline AY360464 & AY360464 & 0.41 & $8.63 \mathrm{E}-05$ & Hypothetical protein LOC146177-like protein mRNA \\
\hline TGFB3 & NM_003239 & 0.41 & $2.95 \mathrm{E}-05$ & Transforming growth factor, beta 3 (TGFB3) \\
\hline TLL1 & NM_012464 & 0.41 & $9.92 \mathrm{E}-05$ & Tolloid-like 1 (TLL1) \\
\hline Clorf1 & U88965 & 0.40 & $4.34 \mathrm{E}-07$ & $\mathrm{PO} 42$ gene \\
\hline FLJ11383 & AK021445 & 0.40 & $8.08 \mathrm{E}-05$ & $\begin{array}{l}\text { cDNA FLJ11383 fis, clone HEMBA1000518, weakly similar to PECA- } \\
\text { NEX protein }\end{array}$ \\
\hline HPS3 & NM_032383 & 0.40 & $3.81 \mathrm{E}-05$ & Hermansky-Pudlak syndrome 3 (HPS3) \\
\hline RSBN1 & NM_018364 & 0.40 & $2.94 \mathrm{E}-05$ & Hypothetical protein FLJ11220 (FLJ11220) \\
\hline CACNG7 & NM_031896 & 0.39 & $1.27 \mathrm{E}-07$ & Calcium channel, voltage-dependent, gamma subunit 7 (CACNG7) \\
\hline EFS & NM_005864 & 0.39 & $2.12 \mathrm{E}-07$ & Embryonal Fyn-associated substrate (EFS) \\
\hline ELA2 & NM_001972 & 0.39 & $6.18 \mathrm{E}-07$ & Elastase 2, neutrophil (ELA2) \\
\hline LRRC4 & NM_022143 & 0.39 & $1.43 \mathrm{E}-06$ & Leucine rich repeat containing 4 (LRRC4) \\
\hline MAP4K5 & NM_198794 & 0.39 & $8.47 \mathrm{E}-05$ & Mitogen-activated protein kinase kinase kinase kinase 5 (MAP4K5) \\
\hline A_23_P202572 & A_23_P202572 & 0.38 & $3.90 \mathrm{E}-06$ & Unknown \\
\hline EVI2B & NM_006495 & 0.38 & $6.35 \mathrm{E}-05$ & Ecotropic viral integration site 2B (EVI2B) \\
\hline FLJ20619 & NM_017904 & 0.38 & $5.58 \mathrm{E}-05$ & Hypothetical protein FLJ20619 (FLJ20619) \\
\hline LOC51619 & NM_015983 & 0.38 & $1.20 \mathrm{E}-06$ & Ubiquitin-conjugating enzyme HBUCE1 (LOC51619) \\
\hline UNQ689 & AY358528 & 0.38 & $1.64 \mathrm{E}-06$ & Clone DNA66660 RSTI689 (UNQ689) \\
\hline USP44 & NM_032147 & 0.38 & $5.64 \mathrm{E}-07$ & Ubiquitin specific protease 44 (USP44) \\
\hline ADAM19 & NM_023038 & 0.37 & $1.81 \mathrm{E}-07$ & A disintegrin and metalloproteinase domain 19 (meltrin beta) (ADAM19) \\
\hline BC039714 & ВC039714 & 0.37 & $3.14 \mathrm{E}-06$ & cDNA clone MGC:47794 IMAGE:5585073 \\
\hline C1QB & NM_000491 & 0.37 & $5.73 \mathrm{E}-09$ & Complement component 1 , q subcomponent, beta polypeptide (C1QB) \\
\hline CD160 & NM_007053 & 0.37 & $1.14 \mathrm{E}-07$ & CD160 antigen (CD160) \\
\hline MGC40179 & NM_173472 & 0.37 & $8.87 \mathrm{E}-07$ & Hypothetical protein MGC40179 (MGC40179) \\
\hline PDZK10 & AB002314 & 0.37 & $2.16 \mathrm{E}-05$ & mRNA for KIAA0316 protein \\
\hline A_23_P212149 & A_23_P212149 & 0.36 & $5.97 \mathrm{E}-05$ & Unknown \\
\hline A_23_P89841 & A_23_P89841 & 0.36 & $4.64 \mathrm{E}-06$ & Unknown \\
\hline DKFZP761H1710 & NM_031297 & 0.36 & $3.42 \mathrm{E}-12$ & Hypothetical protein DKFZp761H1710 (DKFZP761H1710) \\
\hline SLC18A2 & NM_003054 & 0.36 & $9.80 \mathrm{E}-05$ & Solute carrier family 18 (vesicular monoamine), member 2 (SLC18A2) \\
\hline TCN1 & NM_001062 & 0.36 & $1.98 \mathrm{E}-08$ & Transcobalamin I (vitamin B12 binding protein, R binder family) (TCN1) \\
\hline ZNF354B & NM_058230 & 0.36 & $4.88 \mathrm{E}-06$ & Zinc finger protein 354B (ZNF354B) \\
\hline ABCA13 & NM_152701 & 0.35 & $1.12 \mathrm{E}-06$ & ATP binding cassette gene, sub-family A ( $\mathrm{ABC} 1)$, member 13 ( $\mathrm{ABCA} 13$ ) \\
\hline AF090929 & AF090929 & 0.35 & $2.90 \mathrm{E}-07$ & Clone HQ0477 PRO0477p mRNA \\
\hline ВC032472 & ВC032472 & 0.35 & $9.92 \mathrm{E}-06$ & $\begin{array}{l}\text { Similar to caspase } 4 \text {, apoptosis-related cysteine protease, clone IM- } \\
\text { AGE:5216666 }\end{array}$ \\
\hline MGC34837 & NM_152377 & 0.35 & $5.69 \mathrm{E}-05$ & Hypothetical protein MGC34837 (MGC34837) \\
\hline TAL1 & NM_003189 & 0.35 & $3.85 \mathrm{E}-08$ & T-cell acute lymphocytic leukemia 1 (TAL1) \\
\hline TNFSF6 & NM_000639 & 0.35 & $1.29 \mathrm{E}-05$ & Tumor necrosis factor (ligand) superfamily, member 6 (TNFSF6) \\
\hline D82326 & D82326 & 0.34 & $7.13 \mathrm{E}-06$ & mRNA for $\mathrm{Na}^{+}$-independent neutral and basic amino acid transporter \\
\hline TTC18 & NM_145170 & 0.34 & $8.71 \mathrm{E}-07$ & Tetratricopeptide repeat-containing protein (LOC118491) \\
\hline
\end{tabular}


Table 2. Continued.

\begin{tabular}{|c|c|c|c|c|}
\hline Gene name & Accession no. & Ratio & $p$ Value & Description \\
\hline ADAMTS3 & NM_014243 & 0.33 & $4.34 \mathrm{E}-06$ & $\begin{array}{l}\text { A disintegrin-like and metalloprotease (reprolysin type) with thrombo- } \\
\text { spondin type } 1 \text { motif, } 3 \text { (ADAMTS3) }\end{array}$ \\
\hline AGPAT3 & NM_020132 & 0.33 & $1.43 \mathrm{E}-05$ & 1-Acylglycerol-3-phosphate O-acyltransferase 3 (AGPAT3) \\
\hline BC063022 & BC063022 & 0.33 & $3.78 \mathrm{E}-06$ & cDNA clone IMAGE:5246259 \\
\hline MFAP4 & NM_002404 & 0.32 & $4.90 \mathrm{E}-06$ & Microfibrillar-associated protein 4 (MFAP4) \\
\hline DIAPH2 & NM_007309 & 0.31 & $1.82 \mathrm{E}-05$ & Diaphanous homolog 2 (Drosophila) (DIAPH2) \\
\hline GUCY1A2 & NM_000855 & 0.31 & $1.81 \mathrm{E}-06$ & Guanylate cyclase 1, soluble, alpha 2 (GUCY1A2) \\
\hline MGC35030 & ВC042481 & 0.31 & $2.82 \mathrm{E}-08$ & $\begin{array}{l}\text { Hypothetical protein MGC35030 (cDNA clone MGC:35030 IM- } \\
\text { AGE:5164982) }\end{array}$ \\
\hline SIN3B & АВ014600 & 0.31 & $2.27 \mathrm{E}-06$ & mRNA for KIAA0700 protein \\
\hline SOCS4 & NM_080867 & 0.31 & $6.50 \mathrm{E}-05$ & Suppressor of cytokine signaling 4 (SOCS4) \\
\hline A_23_P253353 & A_23_P253353 & 0.30 & $6.70 \mathrm{E}-11$ & Unknown \\
\hline EMX2 & NM_004098 & 0.30 & $4.25 \mathrm{E}-05$ & Empty spiracles homolog 2 (Drosophila) (EMX2) \\
\hline FLJ22843 & AK026254 & 0.30 & $6.67 \mathrm{E}-06$ & cDNA: FLJ22601 fis, clone HSI04471 \\
\hline GSDM1 & NM_178171 & 0.30 & $8.77 \mathrm{E}-09$ & Gasdermin (GSDM) \\
\hline HLF & NM_002126 & 0.30 & $4.94 \mathrm{E}-07$ & Hepatic leukemia factor (HLF) \\
\hline SAA4 & NM_006512 & 0.30 & $3.45 \mathrm{E}-05$ & Serum amyloid A4, constitutive (SAA4) \\
\hline SH3GL2 & NM_003026 & 0.30 & $2.64 \mathrm{E}-05$ & SH3-domain GRB2-like 2 (SH3GL2) \\
\hline ACMSD & NM_138326 & 0.29 & $1.65 \mathrm{E}-06$ & Aminocarboxymuconate semialdehyde decarboxylase (ACMSD) \\
\hline ADAM20 & NM_003814 & 0.29 & $5.31 \mathrm{E}-06$ & A disintegrin and metalloproteinase domain 20 (ADAM20) \\
\hline C15orf26 & NM_173528 & 0.28 & $7.14 \mathrm{E}-05$ & Hypothetical protein FLJ38615 (FLJ38615) \\
\hline A_23_P29907 & A_23_P29907 & 0.27 & $6.46 \mathrm{E}-08$ & Unknown \\
\hline AX721299 & AX721299 & 0.27 & $7.60 \mathrm{E}-05$ & Sequence 259 from Patent WO0220754 \\
\hline C6orf97 & NM_025059 & 0.27 & $9.23 \mathrm{E}-06$ & Chromosome 6 open reading frame 97 (C6orf97) \\
\hline LGALS14 & NM_020129 & 0.27 & $5.56 \mathrm{E}-06$ & Placental protein 13-like protein (PPL13) \\
\hline SLC15A3 & NM_016582 & 0.27 & $1.03 \mathrm{E}-10$ & Solute carrier family 15, member 3 (SLC15A3) \\
\hline $\mathrm{ABCC} 13$ & NM_138726 & 0.25 & $7.39 \mathrm{E}-06$ & ATP-binding cassette, sub-family C (CFTR/MRP), member 13 (ABCC13) \\
\hline NM_152768 & NM_152768 & 0.25 & $2.33 \mathrm{E}-06$ & Hypothetical protein FLJ25378 (FLJ25378) \\
\hline PKHD1 & NM_138694 & 0.25 & $8.75 \mathrm{E}-05$ & Polycystic kidney and hepatic disease 1 (autosomal recessive) (PKHD1) \\
\hline ABCA10 & NM_080282 & 0.24 & $2.86 \mathrm{E}-05$ & ATP-binding cassette, sub-family A (ABC1), member 10 (ABCA10) \\
\hline BMPR1B & NM_001203 & 0.24 & $3.08 \mathrm{E}-07$ & Bone morphogenetic protein receptor, type IB (BMPR1B) \\
\hline C14orf148 & NM_138791 & 0.24 & $5.68 \mathrm{E}-06$ & Hypothetical protein FLJ32809 (LOC122945) \\
\hline FGF5 & NM_004464 & 0.24 & $2.93 \mathrm{E}-09$ & Fibroblast growth factor 5 (FGF5) \\
\hline ADAMTS9 & NM_020249 & 0.23 & $6.69 \mathrm{E}-05$ & $\begin{array}{l}\text { A disintegrin-like and metalloprotease (reprolysin type) with thrombo- } \\
\text { spondin type } 1 \text { motif, } 9 \text { (ADAMTS9) }\end{array}$ \\
\hline CPB1 & NM_001871 & 0.23 & $5.82 \mathrm{E}-09$ & Carboxypeptidase B1 (tissue) (CPB1) \\
\hline FMNL3 & NM_175736 & 0.23 & $1.84 \mathrm{E}-07$ & Formin-like 3 (FMNL3) \\
\hline L17325 & L17325 & 0.23 & $7.47 \mathrm{E}-05$ & Pre-T/NK cell associated protein (1D12A2) \\
\hline SEMG1 & NM_003007 & 0.23 & $4.55 \mathrm{E}-05$ & Semenogelin I (SEMG1) \\
\hline SLC7A3 & NM_032803 & 0.23 & $2.09 \mathrm{E}-05$ & $\begin{array}{l}\text { Solute carrier family } 7 \text { (cationic amino acid transporter, y }+ \text { system), } \\
\text { member } 3 \text { (SLC7A3) }\end{array}$ \\
\hline ZNF141 & NM_003441 & 0.23 & $2.11 \mathrm{E}-05$ & Zinc finger protein 141 (clone pHZ-44) (ZNF141) \\
\hline DMXL1 & NM_005509 & 0.22 & $1.45 \mathrm{E}-07$ & Dmx-like 1 (DMXL1) \\
\hline GPC3 & NM_004484 & 0.22 & $3.05 \mathrm{E}-06$ & Glypican 3 (GPC3) \\
\hline NEGR1 & NM_173808 & 0.22 & $5.06 \mathrm{E}-05$ & Neuronal growth regulator 1 (NEGR1) \\
\hline PDZK1 & NM_002614 & 0.22 & $2.16 \mathrm{E}-05$ & PDZ domain containing 1 (PDZK1) \\
\hline RFPL2 & NM_006605 & 0.22 & $8.26 \mathrm{E}-05$ & Ret finger protein-like 2 (RFPL2) \\
\hline ZNF167 & NM_018651 & 0.22 & $3.58 \mathrm{E}-05$ & Zinc finger protein 167 (ZNF167) \\
\hline MYO3B & NM_138995 & 0.21 & $3.06 \mathrm{E}-07$ & Myosin IIIB (MYO3B) \\
\hline
\end{tabular}


Table 2. Continued.

\begin{tabular}{lllll}
\hline Gene name & Accession no. & Ratio & $p$ Value & Description \\
\hline AK025116 & AK025116 & 0.20 & $9.77 \mathrm{E}-07$ & cDNA: FLJ21463 fis, clone COL04765 \\
C20orf17 & NM_173485 & 0.20 & $4.87 \mathrm{E}-05$ & Chromosome 20 open reading frame 17 (C20orf17) \\
CASP8 & NM_033357 & 0.20 & $1.57 \mathrm{E}-05$ & Caspase 8, apoptosis-related cysteine protease (CASP8) \\
GPR155 & NM_152529 & 0.20 & $1.42 \mathrm{E}-09$ & G protein-coupled receptor 155 (GPR155) \\
NTF5 & NM_006179 & 0.20 & $2.06 \mathrm{E}-06$ & Neurotrophin 5 (neurotrophin 4/5) (NTF5) \\
RFPL3 & NM_006604 & 0.20 & $2.77 \mathrm{E}-07$ & Ret finger protein-like 3 (RFPL3) \\
LOC162967 & NM_207333 & 0.19 & $1.57 \mathrm{E}-12$ & Hypothetical protein LOC162967 (LOC162967) \\
IL6ST & NM_002184 & 0.18 & $1.50 \mathrm{E}-07$ & Interleukin 6 signal transducer (gp130, oncostatin M receptor) (IL6ST) \\
PF4 & NM_002619 & 0.18 & $7.15 \mathrm{E}-14$ & Platelet factor 4 (chemokine (C-X-C motif) ligand 4) (PF4) \\
HSD3B1 & NM_000862 & 0.17 & $3.81 \mathrm{E}-07$ & Hydroxy-delta-5-steroid dehydrogenase, 3 beta-and steroid delta-isomer- \\
& & & & ase 1 (HSD3B1) \\
THC1910111 & THC1910111 & 0.17 & $6.32 \mathrm{E}-09$ & BC022679 D13Ertd275e protein \{Mus musculus \\
F13B & NM_001994 & 0.16 & $3.00 \mathrm{E}-08$ & Coagulation factor XIII, B polypeptide (F13B) \\
ZNF41 & NM_153380 & 0.13 & 9.11E-11 & Zinc finger protein 41 (ZNF41) \\
\hline
\end{tabular}

${ }^{\mathrm{a}}$ The down-regulated genes were significantly expressed in agreement with RT-qPCR result.

lipoprotein receptor-related protein 6 (LRP6). They were down-regulated in arbutin-treated cells and have been found to be the tumor suppressor genes in the regulation of carcinogenesis mechanism. In addition, four differentially expressed genes were classified by BGSSJ program and showed the localization in subcellular region, except that CLECSF7 was not found in the classification. AKT1 and FGFR3 were found to be located in the organelle and extracellular regions, respectively. The molecular functions of those genes were involved in binding, catalytic activity and signal transducer activity, and their biological processes were involved in physiological process, cellular process, regulation of biological process and development.

Correlation of differentially expressed genes with signaling pathways of malignant melanogenesis and tumerigenesis

Combining the pathway databases of BioCarta, KEGG and the PubMed literatures, we built the hypothetical model of signaling pathway in the cell cycle and anti-apoptosis in tumorigenesis, in which the differentially expressed genes of AKT1, FGFR3 and LRP6 in arbutin-treated A375 cells are correlated in this pathway (Figure 4). Our hypothetical model suggests that the arbutinresponsive genes of AKT1, FGFR3 and LRP6 are correlated with the AKT signaling pathway,
RAS, MAPK and WNT signaling pathways, respectively. FGFR3 and LRP6 normally activated in the membrane region and mediated the correlated genes to the downstream pathways of RAS, MAPK and AKT. The down-regulation of these genes may lead to the suppression of cell proliferation, survival, differentiation and apoptosis of the arbutin-treated A375 cells. Therefore, AKT1, FGFR3 and LRP6 play a key role in the regulation of both malignant melanognesis and tumorigenesis. They may become useful candidate markers for early diagnostic and therapeutic applications of melanoma carcinogenesis.

\section{Discussion}

For the cell treatment, we examined the effect of arbutin concentrations on the growth inhibition of A375 cells and those concentrations did not strongly inhibit cell growth even though the incubation time was up to $72 \mathrm{~h}$. We used the concentration of $8 \mu \mathrm{g} / \mathrm{ml}$ arbutin because (i) this was the same concentration as our previous study of kojic acid [11], in which this concentration $(8 \mu \mathrm{g} / \mathrm{ml}$ or $0.8 \% \mathrm{w} / \mathrm{v})$ was less than the saftety recommendation of $1 \%$ prescription in human skin care product [10], (ii) this concentration inhibited cell growth with an inhibition of less than $10 \%$ and no morpholical change of cells, and (iii) it is avoid the differential gene expression data resulting from cell death response of the 

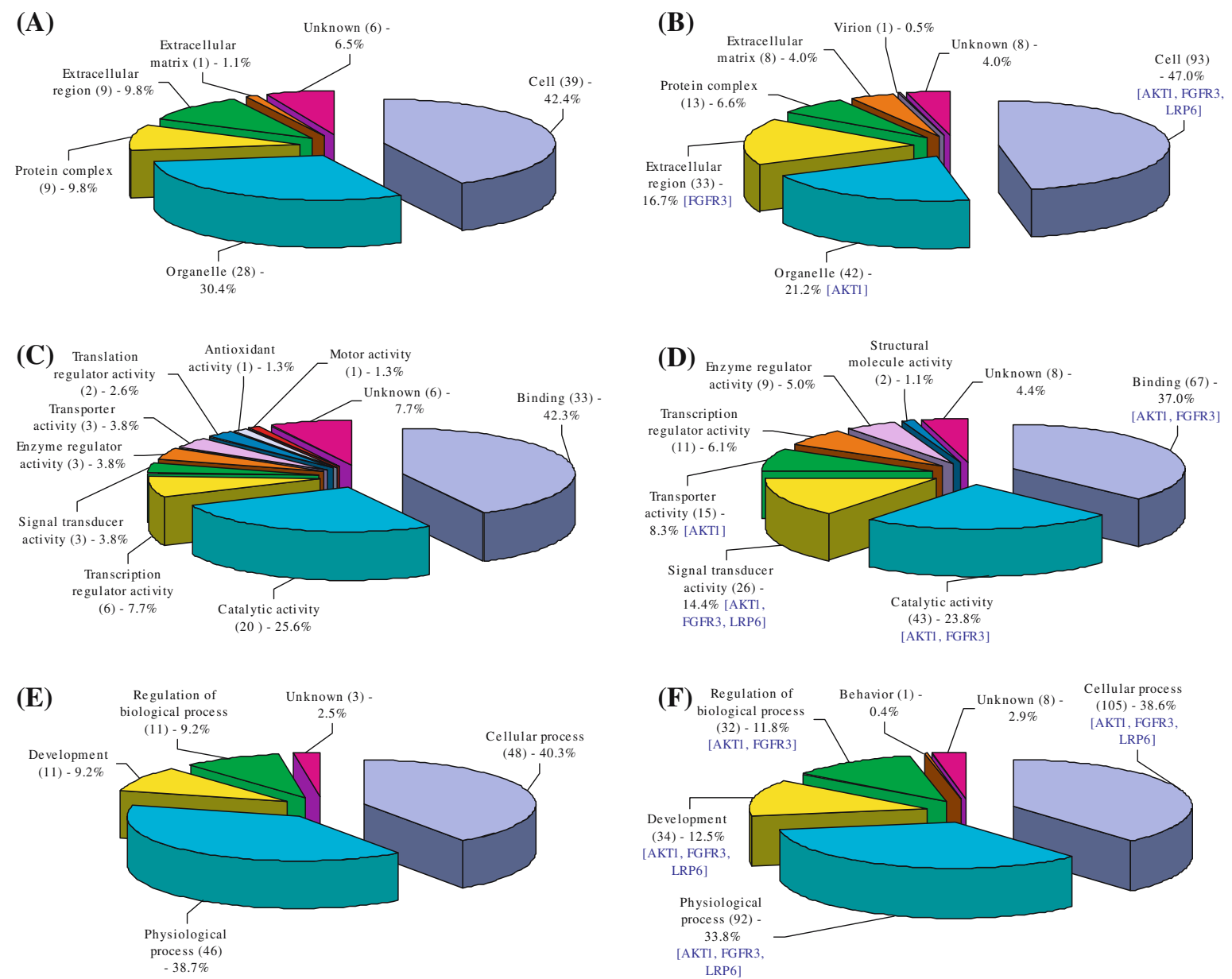

Figure 3. Category classification of up- and down-regulated genes in arbutin-treated A375 cells using the in-house BGSSJ program. The up- and down-regulated genes are classified according to cellular component (A, B), molecular function (C, D), and biological process (E, F), respectively. The following numbers are the classified genes and the percentage of genes in each category. Three down-regulated genes of AKT1, FGFR3 and LRP6 can be classified into each category.

cytotoxicity of a high concentration of arbutin. Under this consideration, the concentration of $8 \mu \mathrm{g} / \mathrm{ml}$ arbutin that is safe for use on human skin was used to study the genotoxic effect on gene expression profiling in A375 cells for exam- ining the differential gene expression and another side-effect through the signaling pathways for cancer therapy. In order to study the effect of arbutin on the gene expression level of A375 cells, the time point of $24 \mathrm{~h}$ after arbutin treatment was

Table 3. Comparison of gene expression level of four differentially expressed genes in arbutin-treated A375 cells by microarray and RT-qPCR analysis.

\begin{tabular}{llllll}
\hline Gene name & Accessions & Description & $p$ Value & Microarray & RT-qPCR \\
\hline 1. AKT1 & NM_005163 & v-Akt murine thymoma viral oncogene homolog 1 & $2.14 \mathrm{E}-405$ & 0.56 & 0.63 \\
2. CLECSF7 & NM_130441 & $\begin{array}{l}\text { C-type (calcium dependent, carbohydrate-recognition domain) } \\
\text { lectin, superfamily member 7, transcript variant 1 }\end{array}$ & $2.09 \mathrm{E}-05$ & 0.53 & 0.52 \\
3. FGFR3 & NM_000142 & $\begin{array}{l}\text { FGFR3 (achondroplasia, thanatophoric dwarfism), transcript } \\
\text { variant 1 }\end{array}$ & $8.82 \mathrm{E}-07$ & 0.49 & 0.43 \\
4. LRP6 & NM_002336 & LRP6 & $3.36 \mathrm{E}-06$ & 0.52 & 0.60 \\
\hline
\end{tabular}




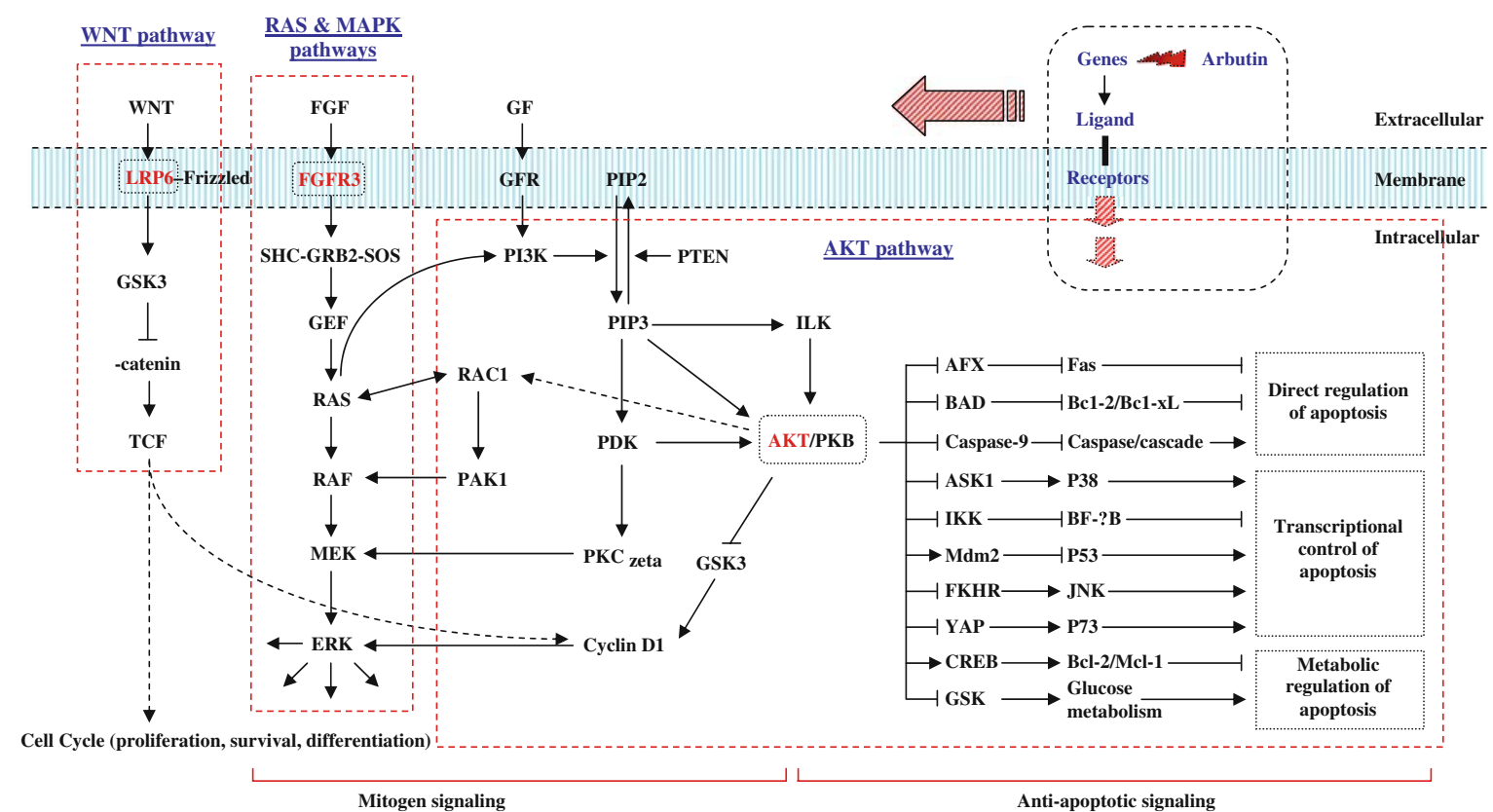

Figure 4. Hypothetical pathways of arbutin-responsive genes (AKT1, FGFR3 and LRP6) in A375 cells correlated with AKT, WNT, RAS and MAPK major signaling pathways in malignant melanogenesis and tumerigenesis. Abbreviations: FGF, fibroblast growth factor; GEF, guanine nucleotide exchange factor; GF, growth factor; GFR, growth factor receptor; GRB2, growth factor receptor-bound protein 2; GSK3, glycogen synthase kinase 3; ILK, integrin-linked kinase; MAPK, mitogen-activated protein kinase 3; PI3K, phosphoinoside-3 kinase; PIP2, phosphatidylinositol-4,5-biphosphate; PIP3, phosphatidylinositol-3,4,5-triphosphate; PDK-1, phosphainositide-dependent kinase-1; PKC, protein kinase C; PTEN, phosphatase and tensin homolog; SON, son of sevenless homolog 1; TCF, transcription factor 7.

chosen for isolating the RNA from cells and studying the gene expression level using microarray analysis.

The changes of differentially expressed genes, which were validated by RT-qPCR analysis, gave the confirmatory quantitative results under stringent condition and revealed that the quantity or expression level of arbutin-responsive genes agreed with the DNA microarray data. It indicated that the validated genes in the robust biomarkers lists obtained precise data. Meanwhile, four significantly arbutin-responsive genes were found to be down-regulated in arbutin-treated A375 cells, and most of the genes are highly effective to the regulation of malignant melanogenesis and/or tumorigenesis process.

AKT1 (v-akt murine thymoma viral oncogene homolog 1 or serine/threonine protein kinase PKB) is frequently up-regulated in human tumors and has been shown to accelerate cell proliferation and to suppress programmed cell death. [12-14]. The gene ontology of its biological process involved in the protein amino acid phosphorylation, nitric oxide biosynthesis, anti-apoptosis, signal transduction and G-protein coupled receptor protein signaling pathway. Its activation via the $\mathrm{AKT} / \mathrm{PKB}$ signaling pathway is triggered through the engagement of receptor tyrosine kinases by peptide growth factors and cytokines, and possesses a vital role in human malignancy tumorigenesis [15-17]. Consequently, the downregulated AKT1 gene in arbutin-treated A375 cells may suppress the tumor progression of malignant transformation in melanoma cells [18-20]. Likewise, AKT1 has also been classified as a tumor suppressor gene in a wide variety of tumor cells, such as breast cancer cells, nonsmall cell lung cancer cells and pancreatic adenocarcinoma, and its down-regulation was shown to suppress the malignant progression of tumorigenesis [21-23].

C-type lectin, superfamily member 7 (CLECSF7) is a novel C-type lectin gene that maps close to the natural killer gene complex on human chromosome located at 12p13.2-p12.3 [24]. The protein encoding CLECSF7 gene, called C-type lectin domain family 4 member C (CLEC4C), is the membrane protein and involved in an oligosaccharide-recognition mechanism [25]. This 
Table 4. Comparison of differentially expressed genes in arbutin- and kojic acid-treated A375 cells and category classification of matched genes.

\begin{tabular}{|c|c|c|c|c|}
\hline \multirow[t]{2}{*}{ Total } & \multicolumn{2}{|c|}{ Up-regulated genes } & \multicolumn{2}{|c|}{ Down-regulated genes } \\
\hline & Arbutin & Kojic acid & Arbutin & Kojic acid \\
\hline 1. Number & 88 & 136 & 236 & 225 \\
\hline 2. Matched genes & \multicolumn{2}{|c|}{18} & \multicolumn{2}{|c|}{98} \\
\hline 3. \% Matching & 20.45 & 13.24 & 41.53 & 43.56 \\
\hline \multicolumn{5}{|l|}{ 4. Category classification of matched genes } \\
\hline (a) Cellular component & \multicolumn{2}{|c|}{$15(100 \%)$} & \multicolumn{2}{|c|}{$70(100 \%)$} \\
\hline Cell & \multicolumn{2}{|c|}{$7(46.67 \%)$} & \multicolumn{2}{|c|}{$39(55.71 \%)$} \\
\hline Extracellular region & \multicolumn{2}{|c|}{$3(20.00 \%)$} & \multicolumn{2}{|c|}{$10(14.29 \%)$} \\
\hline Organelle & \multicolumn{2}{|c|}{$3(20.00 \%)$} & \multicolumn{2}{|c|}{$11(15.71 \%)$} \\
\hline Extracellular matrix & \multicolumn{2}{|c|}{$1(6.67 \%)$} & \multicolumn{2}{|c|}{$5(7.14 \%)$} \\
\hline Protein complex & \multicolumn{2}{|c|}{$1(6.67 \%)$} & \multicolumn{2}{|c|}{$4(5.71 \%)$} \\
\hline Virion & \multicolumn{2}{|c|}{-} & \multicolumn{2}{|c|}{$1(1.43 \%)$} \\
\hline (b) Molecular function & \multicolumn{2}{|c|}{$15(100 \%)$} & \multicolumn{2}{|c|}{$60(100 \%)$} \\
\hline Binding & \multicolumn{2}{|c|}{$8(53.33 \%)$} & \multicolumn{2}{|c|}{$23(38.33 \%)$} \\
\hline Catalytic activity & \multicolumn{2}{|c|}{$4(26.67 \%)$} & \multicolumn{2}{|c|}{$13(21.67 \%)$} \\
\hline Transcription regulator activity & \multicolumn{2}{|c|}{$1(6.67 \%)$} & \multicolumn{2}{|c|}{$4(6.67 \%)$} \\
\hline Transporter activity & \multicolumn{2}{|c|}{$1(6.67 \%)$} & \multicolumn{2}{|c|}{$3(5.00 \%)$} \\
\hline Signal transducer activity & \multicolumn{2}{|c|}{-} & \multicolumn{2}{|c|}{$13(21.67 \%)$} \\
\hline Structural molecule activity & \multicolumn{2}{|c|}{$1(6.67 \%)$} & \multicolumn{2}{|c|}{$1(1.67 \%)$} \\
\hline Enzyme regulator activity & & & & \\
\hline (c) Biological function & & & & \\
\hline Physiological process & & & & \\
\hline Cellular process & & & & \\
\hline Regulation of biological process & & & & \\
\hline Development & & & & \\
\hline
\end{tabular}

protein could interact with blood DC antigen type2 (BDCA-2) receptor and involve in the target ligand into antigen processing and peptide loading compartments for presentation to $\mathrm{T}$ cells [26], in which its activation mediate induction of IFNalpha/beta expression in plasmacytoid dendritic cells in the downstream pathway of apoptosis [27-29]. The down-regulated CLECSF7 gene in arbutin-treated A375 cells may be effective to the immune system and may inhibit the apoptosis of melanogenesis.

FGFR3 is one of the four high affinity tyrosine kinase receptors for the FGF family of ligands. On ligand stimulation, it undergoes dimerization and tyrosine autophosphorylation that result in cell proliferation or differentiation, depending on the cell context [30, 31]. The extracellular portion of the protein encoded by FGFR3 gene interacts with fibroblast growth factors, sets in motion an acidic and basic fibroblast growth hormone and plays a role in bone development and maintenance [32, 33]. The inhibition of FGFR 3 also induced differentiation and apoptosis in multiple myeloma and is treated as an oncogene that contributes to tumor progression in multiple myeloma including human breast cancer [34-36]. Therefore, the downregulated FGFR3 gene may suppress the tumor progression of malignant transformation in melanoma cells.

LRP6 is a member of the expanding LDL receptor family and functions as an indispensable co-receptor for the $\mathrm{Wnt} /$ beta catenin signaling pathway [37-39]. It has been found to be a candidate oncogenes that promoted cancer cell proliferation and tumorigenesis by altering $\beta$-catenin subcellular distribution. In the absence or the deactivating of Wnts, $\beta$-catenin is phosphorylated by multiprotein complex, and leads to 
suppress the tumorigenesis [40-43]. Thus, the down-regulated LRP6 gene in arbutin-treated A375 cells may be a key mediator in suppression of tumorigenesis of malignant transformation in melanoma cells.

According to our finding, we proposed the hypothetical model of signaling pathways of arbutin-responsive genes (AKT1, FGFR3 and LRP6) in A375 melanoma cells which were correlated with the major signaling pathways in cell cycle processes including proliferation, survival, differentiation, apoptosis and malignancy of melanogenesis (Figure 4). The AKT1 was normally activated via AKT signaling pathway that correlated with the upstream signaling pathways of RAS, MAPK, MEK and ERK [15-17]. The FGFR3 was correlated with several pathways, such as the MAPK, phospholipase $\mathrm{C} \gamma, \mathrm{RACl}$ and AKT signaling pathways [30, 31]. The LRP6 is correlated with Wnt and MAPK signaling pathways [41-44]. Thus, this hypothetical model of signaling pathways is a simplified model which can represent the correlation of arbutinresponsive genes with other pathways and provides a clearer understanding of the arbutin-suppression effect on malignancy of melanocytic tumorigenesis. In addition, the CLECSF7 gene was not correlated with this hypothetical model but the deactivated CLECSF7 gene may correlate with another signaling pathway, occurring apoptosis and tumor suppression. Therefore, four down-regulated genes served as key mediators in the cell cycle's signaling pathways and possessed the biological function in the suppression of malignant transformation in arbutin-treated A375 cells.

Moreover, according to our previous study of A375 cells treated with kojic acid [11], we also compared the biological effects of arbutin and kojic acid on the gene expression in A375 cells, in which the same conditions of concentrations, cell treatment and microarray were used. It is the first study of comparative genotoxic effects between arbutin and kojic acid. The purpose of this comparison is to investigate the correlated genotoxic effects on gene expression profiling through the biological function of matched genes in the suppression of tumorigenesis. The comparison of differentially expressed genes between arbutin-and kojic acid-treated A375 cells showed the matched genes of 18 up-regulated genes and 98 downregulated genes, including four significantly arbutin-responsive genes (AKT1, CLECSF7, FGFR3 and LRP6) (Table 4). The matched number of down-regulated genes was 5.4-fold of up-regulated genes and the matching percentages of downregulated genes in arbutin and kojic acid were up to $40 \%$, which may indicate the same direction of suppression of tumorigenesis in A375 cells. Although the comparison of differentially expressed genes according to category classification may not give any significant information, the category classification of matched genes can explain the similar molecular functions and biological functions of differentially expressed genes in both of arbutin-and kojic acid-treated A375 cells. Interesting, FGFR3 gene was found in both of treatments, in which FGFR3 gene may be an important key in the regulation of tumor progression of malignant transformation in melanoma cells. Therefore, we suggest that arbutin and kojic acid gave some biological effect on A375 cells with the similar differential gene expression profiling but the regulation of tumor progression may be regulated by different genes or signaling pathways.

In conclusion, we used the high throughput analysis of DNA microarray and bioinformatic tools for a global analysis of differentially expressed genes in arbutin treated A375 malignant melanoma cells. These genes were classified the gene oncology and led to an exploration of more valuable data in the regulation of melanoma carcinogenesis. In addition, four down-regulated genes served as candidate tumor suppressor genes in A375 cells after arbutin treatment. They may deactivate the regulation of malignant tumorigenesis in human malignant melanoma cells and may become useful markers for further diagnostic and therapeutic applications. Moreover, the genotoxic effect of arbutin on gene expression profiling of A375 cells was similar to kojic acid effect, which may indicate the similar regulation of malignant tumorigenesis. However, we will conduct further studies on the effects of arbutin on the biological and molecular mechanisms of human skin cells, and also examine other biological characterizations of arbutin for therapeutic applications.

\section{References}

1. Tomita K., Fukuda M. and Kawasaki K., Mechanism of arbutin inhibitory effect on melanogenesis and effect on the human skin with cosmetic use. Fragrance J. 6: 72-77, 1990. 
2. Maeda K. and Fukuda M., Arbutin: mechanism of its depigmenting action in human melanocyte culture. J. Pharmacol. Exp. Ther. 276: 765-769, 1996.

3. Ichihashi M., Funasaka Y., Ohashi A., Chacraborty A., Ahmed N.U., Ueda M. and Osawa T., The inhibitory effect of DL-alpha-tocopheryl ferulate in lecithin on melanogenesis. Anticancer Res. 19: 3769-3774, 1999.

4. Sugimoto K.S., Nishimura T., Nomura K., Sugimoto K. and Kuriki T., Inhibitory effects of $\alpha$-arbutin on melanin synthesis in cultured human melanoma cells and a threedimensional human skin model. Biol. Pharm. Bull. 27: 510514, 2004.

5. Brem R., Hildebrandt T., Jarsch M., van Muijen G.N. and Weidle U.H., Identification of metastasis-associated genes by transcriptional profiling of a metastasizing versus a nonmetastasizing human melanoma cell line. Anticancer Res. 21: 1731-1740, 2001.

6. de Wit N.J., Burtscher H.J., Weidle U.H., Ruiter D.J. and van Muigen G.N., Differentially expressed genes identified in human melanoma cell lines with different metastatic behavior using high-density oligonucleotide arrays. Melanoma Res. 12: 57-69, 2002.

7. Kunz M., Ibrahim S.M., Koczan D., Scheid S., Thiesen H.J. and Gross G., DNA microarray technology and its applications in dermatology. Exp. Dermatol. 13: 593-606, 2004.

8. Loveland B.E., Johns T.G., Mackay I.R., Vaillant F., Wang Z.X. and Hertzog P.J., Validation of the MTT dye assay for enumeration of cells in proliferative and antiproliferative assays. Biochem. Int. 27: 501-510, 1992.

9. Dudoit S., Yang Y.H., Speed T.P. and Callow M.J., Statistical methods for identifying genes with differential expression in replicated cDNA microarray experiments. Stat. Sin. 12: 111-139, 2002.

10. Tiedtke J., Morel J. and Marks O., Depigmentation factor bioflavonoids-a safe and effective skin lightener based on encapsulated citrus bioflavonoids. Cosmetochem 2: 12-17, 2004.

11. Cheng S.L., Liu R.H., Sheu J.N., Chen S.T., Sinchaikul S. and Tsay G.J., Toxicogenomics of kojic acid on gene expression profiling of A375 human malignant melanoma cells. Biol. Pharm. Bull. 29: 655-669, 2006.

12. Bellacosa A., Kumar C.C., Di Cristofano A. and Testa J.R., Activation of AKT kinases in cancer: implications for therapeutic targeting. Adv. Cancer Res. 94: 29-86, 2005.

13. Vivanco I. and Sawyers C.L., The phosphatidylinositol 3-kinase AKT pathway in human cancer. Nat. Rev. Cancer. 2: 489-501, 2002.

14. Song G., Ouyang G. and Bao S., The activation of Akt/ PKB signaling pathway and cell survival. J. Cell. Mol. Med. 9: 59-71, 2005.

15. Laprise P., Langlois M.J., Boucher M.J., Jobin C. and Rivard N., Down-regulation of MEK/ERK signaling by E-cadherin-dependent PI3K/Akt pathway in differentiating intestinal epithelial cells. J. Cell. Physiol. 199: 32-39, 2004.

16. Parsa A.T. and Holland E.C., Cooperative translational control of gene expression by Ras and Akt in cancer. Trends Mol. Med. 10: 607-613, 2004.

17. Giehl K., Oncogenic Ras in tumour progression and metastasis. Biol. Chem. 386: 193-205, 2005.

18. Robertson G.P., Functional and therapeutic significance of Akt deregulation in malignant melanoma. Cancer Metastasis Rev. 24: 273-285, 2005.
19. Liu X., Shi Y., Han E.K., Chen Z., Rosenberg S.H., Giranda V.L., Luo Y. and Ng S.C., Downregulation of Akt1 inhibits anchorage-independent cell growth and induces apoptosis in cancer cells. Neoplasia 3: 278-286, 2001.

20. Aggarwal B.B., Bhardwaj A., Aggarwal R.S., Seeram N.P., Shishodia S. and Takada Y., Role of resveratrol in prevention and therapy of cancer: preclinical and clinical studies. Anticancer Res. 24: 2783-2840, 2004.

21. Liu H., Radisky D.C., Nelson C.M., Zhang H., Fata J.E. and Roth R.A., Mechanism of Akt1 inhibition of breast cancer cell invasion reveals a protumorigenic role for TSC2. Proc. Natl. Acad. Sci. USA 103: 4134 4139, 2006.

22. Balsara B.R., Pei J., Mitsuuchi Y., Page R., Klein-Szanto A., Wang H., Unger M. and Testa J.R., Frequent activation of AKT in non-small cell lung carcinomas and preneoplastic bronchial lesions. Carcinogenesis 25: 20532059, 2004.

23. Ruggeri B.A., Huang L., Wood M., Cheng J.Q. and Testa J.R., Amplification and overexpression of the AKT2 oncogene in a subset of human pancreatic ductal adenocarcinomas. Mol. Carcinog. 21: 81-86, 1998.

24. Fernandes M.J., Iscove N.N., Gingras G. and Calabretta B., Identification and characterization of the gene for a novel c-type lectin (CLECSF7) that maps near the natural killer gene complex on human chromosome 12. Genomics 69: 263-270, 2000.

25. Drickamer K., Evaluation of $\mathrm{Ca}^{2+}$-dependent animal lectins. Prog. Nucl. Acid Res. Mol. Biol. 45: 207-232, 1993.

26. McGreal E.P., Miller J.L. and Gordon S., Ligand recognition by antigen-presenting cell C-type lectin receptors. Curr. Opin. Immunol. 17: 18-24, 2005.

27. Kemp T.J., Elzey B.D. and Griffith T.S., Plasmacytoid dendritic cell-derived IFN- $\alpha$ induces TNF-related apoptosis-inducing ligand/Apo-2L-mediated antitumor activity by human monocytes following $\mathrm{CpG}$ oligodeoxynucleotide stimulation. J. Immunol. 171: 212-218, 2003.

28. Santini S.M., Pucchio T.D., Lapenta C., Parlato S., Logozzi M. and Belardelli F., A new type I IFN-mediated pathway for the rapid differentiation of monocytes into highly active dendritic cells. Stem Cells 21: 357-362, 2003.

29. Arce I., Roda-Navarro P., Montoya M.C., HernanzFalcon P., Puig-Kroger A. and Fernandez-Ruiz E., Molecular and genomic characterization of human DLEC, a novel member of the C-type lectin receptor gene family preferentially expressed on monocyte-derived dendritic cells. Eur. J. Immunol. 31: 2733-2740, 2001.

30. Eswarakumar V.P., Lax I. and Schlessinger J., Cellular signaling by fibroblast growth factor receptors. Cytokine Growth Factor Rev. 16: 139-149, 2005.

31. L'Hote C.G. and Knowles M.A., Cell responses to FGFR3 signaling: growth, differentiation and apoptosis. Exp. Cell. Res. 304: 417-431, 2005.

32. Logie A., Dunois-Larde C., Rosty C., Levrel O., Blanche M., Ribeiro A., Gasc J.M., Jarcano J., Werner S., SastreGarau X., Thiery J.P. and Radvanyi F., Activating mutations of the tyrosine kinase receptor FGFR3 are associated with benign skin tumors in mice and humans. Human Mol. Genet. 14: 1153-1160, 2005.

33. Pandit S.G., Govindraj P., Sasse J., Neame P.J. and Hassell J.R., The fibroblast growth factor receptor, FGFR3, forms gradients of intact and degraded protein across the growth plate of developing bovine ribs. Biochem. J. 361: 231-241, 2002. 
34. Chesi M., Brents L.A., Ely S.A., Bais C., Robbiani D.F., Mesri E.A., Kuehl W.M. and Bergsagel P.L., Activated fibroblast growth factor receptor 3 is an oncogene that contributes to tumor progression in multiple myeloma. Blood 97: 729-736, 2001.

35. Qian S., Somlo G., Zhou B., Zhu L., Mi S., Mo X., Cheung E.M., Qiu W., Lin R.J., Rossi J., Holtz M., Chu P. and Yen Y., Ribozyme cleavage leads to decreased expression of fibroblast growth factor receptor 3 in human multiple myeloma cells, which is associated with apoptosis and downregulation of vascular endothelial growth factor. Oligonucleotides 15: 1-11, 2005.

36. Zhu L., Somlo G., Zhou B., Shao J., Bedell V., Slovak M.L., Liu X., Luo J. and Yen Y., Fibroblast growth factor receptor 3 inhibition by short hairpin RNAs leads to apoptosis in multiple myeloma. Mol. Cancer Ther. 4: 787-798, 2005.

37. He X., Semenov M., Tamai K. and Zeng X., LDL receptorrelated proteins 5 and 6 in $\mathrm{Wnt} / \beta$-catenin signaling: arrows point the way. Development 131: 1663-1677, 2004.

38. Li Y., Lu W., He X., Schwartz A.L. and Bu G., LRP6 expression promotes cancer cell proliferation and tumori- genesis by altering $\beta$-catenin subcellular distribution. Oncogene 23: 9129-9135, 2004.

39. Tamai K., Semenov M., Kato Y., Spokony R., Liu C., Katsuyama Y., Hess F, Saint-Jeannet J.P. and He X., LDL-receptor-related proteins in Wnt signal transduction. Nature 407: 530-535, 2000.

40. Benhaj K., Akcali K.C. and Ozturk M., Redundant expression of canonical Wnt ligands in human breast cancer cell lines. Oncol. Rep. 15: 701-707, 2006.

41 Wodarz A. and Nusse R., Mechanisms of Wnt signaling in development. Annu. Rev. Cell. Dev. Biol. 14: 59-88, 1998.

42. Giles R.H., van Es J.H. and Clevers H., Caught up in a Wnt storm: Wnt signaling in cancer. Biochim. Biophys. Acta 1653: 1-24, 2003.

43. Lustig B. and Behrens J., The Wnt signaling pathway and its role in tumor development. J. Cancer Res. Clin. Oncol. 129: 199-221, 2003.

44. Quaiser T., Anton R. and Kuhl M., Kinases and G proteins join the Wnt receptor complex. Bioessays 28: 339-343, 2006. 